\title{
Heuristics Hindering the Development of Understanding of Molecular Structures in University Level Chemistry Education: The Lewis Structure as an Example
}

\author{
Maarit Karonen 1,*DiD, Mari Murtonen ${ }^{2}$, Ilona Södervik ${ }^{3}$, Marianna Manninen ${ }^{1} \mathbb{D}$ and Mikko Salomäki ${ }^{1, *}$ \\ 1 Department of Chemistry, University of Turku, 20014 Turku, Finland; marianna.i.manninen@utu.fi \\ 2 Department of Teacher Education, University of Turku, 20014 Turku, Finland; marimur@utu.fi \\ 3 Centre for University Teaching and Learning (HYPE), University of Helsinki, 00014 Helsinki, Finland; \\ ilona.sodervik@helsinki.fi \\ * Correspondence: maarit.karonen@utu.fi (M.K.); mikko.salomaki@utu.fi (M.S.)
}

check for

updates

Citation: Karonen, M.; Murtonen,

M.; Södervik, I.; Manninen, M.;

Salomäki, M. Heuristics Hindering

the Development of Understanding

of Molecular Structures in University

Level Chemistry Education: the

Lewis Structure as an Example. Educ.

Sci. 2021, 11, 258. https://doi.org/

10.3390/educsci11060258

Academic Editor: Rüdiger Tiemann

Received: 23 April 2021

Accepted: 21 May 2021

Published: 26 May 2021

Publisher's Note: MDPI stays neutral with regard to jurisdictional claims in published maps and institutional affiliations.

Copyright: (c) 2021 by the authors. Licensee MDPI, Basel, Switzerland. This article is an open access article distributed under the terms and conditions of the Creative Commons Attribution (CC BY) license (https:/ / creativecommons.org/licenses/by/ $4.0 /)$.

\begin{abstract}
Understanding chemical models can be challenging for many university students studying chemistry. This study analysed students' understanding of molecular structures using the Lewis structure as a model, and examined what hinders their understanding. We conducted pre- and posttests to analyse students' conceptions and changes in them. The measures contained multiple-choice questions and drawing tasks testing their understanding of concepts, such as polarity, geometry, charge or formal charge and expanded octet. The pre-test revealed a lack of knowledge and several misconceptions in students' prior knowledge. For example, the concept of polarity was well-known, but the combination of polarity and geometry appeared to be difficult. For some students, the representation of molecules was intuitive and lacking a systematic approach. Certain students used mnemonics and draw ball-and-stick models connected to surficial representations. After the chemistry courses, the conceptions and drawings had generally changed, and the level of the students' knowledge increased markedly. Although, fewer ball-and-stick models were drawn in the posttest, some students still used them. The main result was that students who drew ball-and-stick models in the pre-test were less capable of drawing the correct Lewis structures with electrons in the post-test. In addition, heuristics seem to hinder learning and some concepts, such as resonance, remained difficult. This is probably due to the fact that understanding molecular structures requires systemic understanding, where several matters must be understood at the same time. Our study highlights that the understanding of molecular structures requires conceptual change related to several sub-concepts.
\end{abstract}

Keywords: ball-and-stick model; conceptual change; critical thinking; general learning theories; problem-solving; systemic understanding; university students

\section{Introduction}

Generating representative molecular structures is challenging for many students in introductory level chemistry classes in university. Previous studies have shown that it is typical for many students to utilize simple mnemonics and rules of thumb in chemistry learning [1]. This derives from the fact that often, already at elementary school level, students are introduced to heuristic reasoning strategies in chemistry learning. The problem is that although the use of heuristics allows the solving of simpler problems, they often lead to systematic misconceptions when the contents of the tasks become more complex, as happens at university level learning [2]. However, students seem to utilize oversimplified mnemonics also when the contents to be learned become more complex and utilizing of simple tools and mnemonics is no more meaningful. The use of mnemonics may hinder critical thinking and does not support the development of problem-solving skills [3]. Therefore, this study examines first-year chemistry students' conceptions and the changing 
of these conceptions related to molecular structures utilizing the Lewis structure as a model. Additionally, we examine whether the university chemistry students use simple mnemonic tools and heuristic reasoning when learning molecular structures in the introductory course of chemistry.

\subsection{Understanding Molecular Structures Utilizing Lewis Model Suggests Systemic Understanding}

The Lewis structure was described in the paper of Gilbert N. Lewis titled "The atom and the molecule" as early as in 1916 [4]. The structure was limited originally to electron dot structures for which each atom, except hydrogen and helium, contained eight electrons in the valence shell. The Lewis conceptions were based on the Bohr's atom model and contemporary findings realized as completion of the periodic table. Using his chemical intuition, Lewis was able to construct a credible basis for how covalently bonded atoms are held together in a molecule. Lewis structures are actually very simple when considering heavier second-row elements in the periodic table such as carbon, nitrogen and oxygen, which have $2 \mathrm{~s}$ and $2 \mathrm{p}$ valence shells and no possibility to exceed the electron octet, and hydrogen with predictable duplet formation in its 1s shell. This information alone forms an adequate understanding for drawing the correct structures of organic molecules, at least without drawing free electrons (Kekulé structures) or if resonance should not be applied. However, for some students, the concept of electron octet is not very clear and surface-level coping strategies are used construct the molecular structures [5].

To draw Lewis structures correctly means predicting the number and type of bonds that may be formed around an atom and constructing realistic molecules using given atoms. Based on a correct Lewis structure, one can make predictions about the relation of the molecular structure and its macroscopic behaviour, such as geometry, chemical properties and reactivity of a molecule, representing necessary skills for further development of chemical thinking. However, students often struggle with learning these skills $[1,6]$. Drawing appropriate Lewis structures for complex molecules requires understanding that exceeds simple heuristics and memory rules. Drawing is a process where a student must reflect on various different concepts simultaneously. There may be more realistic ways than drawing for expressing the molecular structure by considering the electron orbitals around atoms and molecules, but those usually need molecular modelling and representation using computers. Even though the Lewis structures are considered as slightly incomplete constructions of reality [7], the Lewis structures are still useful models for predicting molecular structure. Despite the fact that its information on electronic structure is considered overgeneralized [8], in chemistry education, Lewis structures can be considered as a mandatory pedagogical intermediate stage in understanding molecular structure before discovering quantum mechanical world-view. Thus, drawing simplified Lewis structures is a rational pedagogical approach for learning molecular structure using pen and paper, still after over one hundred years.

In chemistry, even a seemingly simple task requires students to organize and synthesize a large amount of information [1]. When it comes to learning molecular structures, students need to combine knowledge related to both molecules' structures and their properties. This means understanding causal explanations between, for example, structures and function by asking questions starting with "what kind of", "how" and "why" is essential. For example: What kind of structure does a certain molecule have? How does structure influence the polarity of the molecule? Thus, although the learning of facts is also important, knowing a system's components alone does not ensure students' understanding of interrelationships and entities $[9,10]$. Systemic understanding means knowledge of how separate concepts interrelate and combine meaningfully to form a complex structure [11,12]. Systemic understanding enables the flexible use of concepts as effective tools instead of static and isolated "islands" of knowledge, a skill that is needed in learning complex molecular structures including several sub-concepts such as resonance and polarity.

The importance of systemic understanding in learning science has become unquestioned among science education researchers over the past decade [13]. However, typically 
scientific phenomena have been investigated utilizing solely multiple-choice questionnaires that typically do not deeply reveal students' misconceptions and lack of knowledge; see, for example, Cooper et al. [6]. Therefore, in this study, different task types were utilized in order to detect students' conceptions together with possible misconceptions and quality of systemic understanding together with conceptual change related to molecular structure. The purpose of this study is to investigate first-year chemistry students' prior conceptions and learning during a course concerning molecular structures with the Lewis structure as a model.

\subsection{High-Level Chemistry Learning Requires Conceptual Change}

A common challenge at universities, especially in introductory courses, is the heterogeneity of students when it comes to their level and quality of prior knowledge related to the topics to be learnt. Research concerning the role of students' pre-instructional conceptions in learning has conclusively shown that the quality of previous knowledge plays a critical role in learning [14]. Thus, students' previous knowledge-a necessary prerequisite for all conceptual learning-may either support learning when in unison with current scientific understanding, or hinder learning if there are discrepancies between the old knowledge and the new information. This paradox of learning [15] poses a challenge for learning and instruction also in higher education.

It is well established in different disciplines that students come to science lessons loaded with expectations, previous knowledge and prior conceptions that in some cases significantly contradict the scientific view [16-24]. Currently, learning researchers have a consensus that the main barrier to learning is often not what the student's knowledge structures lack, but what the student has-namely, alternative conceptual frameworks for understanding the particular phenomenon to be studied [25]. These naïve conceptions may have their origins in previous instructional experiences, when oversimplified mnemonic tools are introduced to the students. Furthermore, textbooks have only a limited opportunity to support the understanding of simultaneous processes, three-dimensional objects and systemic understanding. Hence, learning often requires that one's knowledge structures become radically reorganized and some previous conceptions and beliefs even abandoned. These types of learning processes are described using the theoretical perspective of conceptual change [23,26-29].

Conceptual change refers to a learning process in which the concepts and knowledge structures of the student on a particular phenomenon are profoundly reorganized [29]. Different theoretical models have been developed to describe conceptual change as a type of learning and teaching in science (for a review, see Potvin et al. [30]). According to Chi's well-known model, knowledge can be misconceived at three levels of complexity, including false beliefs, mental models and ontological categories [31]. The most basic level of misconception is the false belief, which is a factual type of error that is relatively easy to correct in belief revision process [31]. A more complex type of misconception is called mental model misconception [31]. The mental model is a representation consisting of multiple propositions and features as well as interrelationships between those features resulting in mental models not being simply a collection of individual beliefs, but a systemic model. Conceptual change at the level of mental models, i.e., mental model transformation, is a challenging process because of the need for systemic-level changes, where interrelations between concepts need to be rearranged. The third and the most complex level of misconceived prior knowledge, according to Chi [31], is the ontological level, where conceptual change requires a category shift from the ontological category to another $[32,33]$. In chemistry, for example, understanding the dual nature of electrons typically requires an ontological shift from the category of "objects" or "particles" that behave according to the laws of classical mechanics to the category of subatomic particles that have a dualistic, wave-particle nature.

Human beings have various ways to reject information that does not fit into their existing knowledge structures and therefore, achieving conceptual change is typically 
very challenging [18]. As a result, instead of constructing a scientific understanding, a learner may construct a so-called synthetic model that has characteristics of both scientific and naïve explanations (see, for example, Vosniadou and Brewer [34]). Synthetic models develop if one adds new information to old knowledge structures and ignores the conflicts between them [34]. Achieving conceptual change usually requires one to be aware of the discrepancy between one's conceptions and the scientific idea and be willing to change one's conceptions to align them better with the science; therefore, reaching conceptual change usually requires systematic and intentional studying and teaching. Even though conceptual change research has become one of the most important areas in science learning and instruction since the 1970s, studies have mainly focused on the learning of students at the elementary school level. In fact, research concerning the role of conceptual change type of learning has almost been neglected in higher education until lately (see, however, Flaig et al. [35]). Previous studies in the context of medicine showed that students who had misconceptions related to basic content had less success in clinical reasoning tasks in later study years [36]. Thus, there is an urgent need to understand conceptual change challenges at the higher education level more profoundly, considering that misconceptions in the early phase of studies may have serious repercussions in the later study phases and in work life.

In order to investigate conceptual understanding related to science concepts in a profound manner, a domain-specific perspective is crucial. This is because the kinds of changes necessary for high-level learning are often fundamentally different for different domains and even sub-domains [37]. However, in the research tradition of conceptual change, the domain-specific perspective has often taken a back seat, meaning that there has been little focus on reflecting questions such as which special characteristics make the learning of certain concepts difficult, which kinds of misconceptions and naïve mnemonics are typical among students and in a larger scale and what the significance of understanding a certain concept for students is. As Duit and Treagust comment [38], in many studies about conceptual change, the major emphasis has been on implementing new instructional methods and not on rethinking the presentation of the particular science topic. This is also the case in research concerning chemistry learning and instruction.

The purpose of this study is to investigate first-year chemistry students' conceptions and changes in their conceptions as a result of an authentic introductory course related to one of the most central contents in chemistry curriculum, namely, molecular structures. Drawing tasks complemented with multiple-choice questions are utilized in order to detect students' conceptions together with typical challenges related to learning certain subconcepts, possible misconceptions as well as the quality of systemic understanding related to the Lewis model. Although being aware that the term misconception is arguable (for example, because learning of science phenomena is a gradual process and certain naïve conceptions can be considered important transitional periods towards a better scientific understanding), we use this term in this paper and define it as a conception that is not in unison with current scientific understanding.

\subsection{Heuristics May Induce Misconceptions in Chemistry Education}

The investigation of the structural characteristics and complexities that contribute significantly to the load in chemistry students creating Lewis structures suggested that heuristics can lead students to focus on irrelevant features and thereby direct them to cognitive biases and incorrect answers, and it called for the better understanding of the full range of heuristics the students are using [39]. Therefore, the second goal of this study is to see whether it is possible to identify certain typical naïve mnemonics, rules of thumb and heuristics underlying and explaining students' misconceptions. Recognizing the origins and characteristics of misconceptions is essential when trying to understand why the learning of certain scientific concepts poses challenges for students and how learning could and should be supported via instruction. According to Guzzetti et al. [40], misconceptions can derive, for example, from previous instructional experiences. This may be the case in learning complex scientific contents such as molecular structures, where 
using of mnemonics, rules of thumb or use of (over)simplification, i.e., heuristics, are typical study methods [6]. In fact, instructors have implemented a range of heuristics that are taught to students to help them construct molecular representations and use them to predict properties [1]. These aids may seemingly support learning, in learning of simple cases, but actually often leads into systematic misconceptions when applied in solving more complex problems [2]. Previous literature study on the misconceptions in chemistry education identified multiple misconceptions and determined several subjects to be abstract and complex for the students, namely dissolution, melting, solubility equilibrium, chemical equilibrium, covalent bonds, ionic bonds, hydrogen bond and its molecular geometry, double and triple bonds, activity, electrolyze and battery [41].

When it comes to the learning of molecular structures, for example, the "octet rule" allows students to construct Lewis structures without having to consider how or why the representation should look this way. For instance, many first-year university course attendees are aware that carbon has four bonds, nitrogen three bonds, oxygen two bonds and hydrogen one bond. This can then be memorized with, for example, a simple HONC1234 acronym (atoms and the number of bonds) or equivalent memorized simplified constructions. The rule could have been omitted from the molecular building blocks that are widely used in chemistry education at the present time. The molecular constructing method based on simple memory rules is completely valid, providing enough explanatory power for the representation of very simple molecules such as $\mathrm{H}_{2} \mathrm{O}$ or $\mathrm{CH}_{4}$ accompanied usually with valid geometrical understanding. Those molecules, among many other simple ones, can be considered as familiar molecules based on the previous education. Their representation is spontaneous and usually error-free. The produced structure is supposedly a product of memory operation and not cognitive reasoning. Additionally, applying oversimplified rules when considering more complex structures leads to misinterpretations. Such heuristics allow rapid decisions and predictions to be made without critical thinking in considering the ideas that allowed their development and thus, they are not explanations for a particular phenomenon or concept [1]. In general, the students may not realize that for even very experienced chemists, the construction of a structure of an unknown molecule is always more like a problem-solving task, not just a memory operation. Thus, their problemsolving skills may remain undeveloped if these mnemonics are used in wrong situations.

Understanding multifaceted chemistry concepts requires much support in the learning environment, such as from learning material. For example, new virtual and augmented reality (VR/AR) technology solutions may bring some aid in the future for presenting molecular structures (e.g., [42]). So far, a great part of learning still occurs through reading, and textbook texts seem to be one of the most important tools in science learning [43-45]. However, throughout the Finnish chemistry education system from elementary school to secondary level, the molecules in the textbooks are often presented as or space-filling three dimensional models. The physical molecular models, such as the ball-and-stick model, are often recommended for use in teaching (e.g., [46]). This approach might give more realistic picture about molecules as geometric objects, but the students might be missing the actual perception of, for example, bonding between atoms. Spheres are generally realized as atoms, but the physical nature of bonds might be obscure. A spherical object in a molecular modelling kit has a certain number of places and directions to insert bonds, guiding one towards a correct three-dimensional structure.

The constructed structures are usually valid. However, problems appear when the electronic structure of the molecule is unusual; for example, $\mathrm{CO}, \mathrm{N}_{2} \mathrm{O}, \mathrm{O}_{3}$ and many ionic compounds, or if the atoms have tendency to form bonds using d-electrons. The Finnish upper secondary school chemistry textbooks clearly describe the covalent bonding concepts and underline the stability of the octet or so-called noble gas structure. The expanded octet is not generally concerned. The bond formation between the second-row elements is described well. However, the systematic approach for producing representative structures for demanding molecules is missing. In some of the textbooks, the emphasis is on two dimensional Kekulé structures combined with three dimensional ball-and-stick 
structures and the Lewis structure is merely presented superficially. As an exception, in one book series, many of the structures are presented as Lewis structures. Thus, there is a great variation in the representation between the sets of textbooks. In general, valence shell repulsion models and the simplest geometries are presented. However, resonance structures are given very little attention at this stage of education. Those structures are often explained and presented using hybridization models. The formal charges are not usually taken into account in molecular structures. Consequently, the very basic concepts of molecular structure are being considered adequately in earlier chemistry classes.

One problem in the first semester chemistry course in the university is that some students previously participated only in mandatory chemistry courses at the secondary level. This usually concerns the students whose main subject of study is biology, biochemistry and geology. They might be missing very essential prior knowledge in chemistry. This may prevent a deeper understanding of chemical concepts and can often lead to the reproduction of isolated facts instead of the achievement of conceptual change.

\subsection{Research Questions}

Based on the premises described above, the purpose of this article is to investigate university students' development of an understanding of molecular structures, and the heuristics hindering the learning on an introductory level chemistry course. The changes in the conceptions are investigated by specific objectives:

1. How do students' concepts and sub-concepts of molecular structures generally develop during a chemistry basics course, and what kind of systematic mistakes and misrepresentations exist?

2. How do the used heuristics affect students' learning of molecular structures?

\section{Materials and Methods}

\subsection{Participants}

The study was performed at a middle-sized Finnish university in 2017. The study was carried out in two first-semester general chemistry courses that were held simultaneously. The students in both courses were mainly college freshmen and sophomores. All students had studied chemistry in upper secondary school, but for some students, there may have been many years between those and the current studies.

Altogether, 200 chemistry majors, minors and open university students (age: 18-45 years, $M=20.81$ ) participated in the study in the pre-test phase. Minor students came from the majors such as biology, biochemistry and geology. A total of 134 of them were women (67\%) and $65(33 \%)$ were men. They were present for the voluntary lectures where the data were collected. In the post-test phase, the data were collected from 79 students and of those, 70 participated in the course exam. Therefore, the final number of students from whom we had complete data for the study was 70 , which accounts for $35 \%$ of all students who participated in the study in the pre-test phase, and $46 \%$ of the students who participated in the exam. The study was performed according to the ethical instructions of the university. All students who participated gave their permission, i.e., filled out a voluntary informed consent form. Participation was voluntary and the students had the option to withdraw from the research at any time.

\subsection{Context and Design}

The study consisted of a pre-test in the beginning and a post-test at the end of an introductory chemistry course. The introductory chemistry course (4 ECTS) lasted 7 weeks and consisted of three lectures per week. Desired learning outcomes were the same for the majors, minors and open university students. For majors, the course contained lecture-based teaching, small group works and demonstrations. The course for minors and open university students consisted of lecture-based teaching and discussions during the lectures. One of the goals was that all students would understand molecular structures after the course. 
The teaching of the courses contained demonstrations and practice of molecule drawing, starting from uncomplicated molecules such as water and ranging to very difficult molecules while including resonance and utilizing the concept of formal charge. The desired learning outcomes of the courses included abilities to manage more difficult atoms such as sulphur, halogens and noble gases. The intention was that after the lectures and practice tasks, the students would no longer be dependent on memory rules for information such as four bonds for carbon. The most important objective of these university courses was to obtain a systematic treatment of atoms in formation of molecular structure and learn the basic and advanced concepts of constructing a representational Lewis structure. The students were encouraged to follow a certain step-by-step pathway towards the correct structure. The steps included counting the valence electrons, selecting the central atom, making decisions on bond order, allocating free electrons, making decisions on resonance and on exceptions on the octet rule and finally counting the formal charges to critically review the reliability of the obtained molecular structure. After completion of these steps, the geometry of the molecule was analysed using the valence shell electron repulsion theory.

The pen-and-paper pre- and post-tests were administered by the teachers to the students in the lecture halls. The same questionnaire was utilized in both tests. It took around $20 \mathrm{~min}$ to complete the questionnaire. The time was not limited. After the course had finished, the students performed an exam including one drawing task that was utilized in this study for the students who participated in the study. The texts written by the students have been translated to English for this article.

\subsection{Measures}

The pre- and post-test questionnaires consisted of background questions (student number, gender, study place (university/open university/other) and previous degree), multiple-choice tasks and drawing tasks. In addition, there was one drawing task as a part of the course exam that was evaluated. The multiple-choice and drawing tasks were designed and formulated so that they measured both sub-concepts and the systemic understanding of the Lewis structure. The sub-concepts, such as the bonds between atoms and the geometry and polarity of the molecule, were determined based on the previous knowledge of a student's learning and the typical mistakes found in the earlier exams of the similar courses. The multiple-choice questions were designed to test student's knowledge about chemical structures (Table 1). The same questions were included in both pre- and post-test questionnaires. The students were able to use the periodic table supplied in the tests, but no other materials were allowed.

Table 1. Number of the multiple-choice question or molecular formulae presented to students, the reason for our choice and the needed student accomplishment.

\begin{tabular}{|c|c|c|}
\hline & $\begin{array}{l}\text { Reason } \\
\text { for Our Choice }\end{array}$ & Needed Student Accomplishment \\
\hline 1 & valence bond & understanding the nature of a bond \\
\hline 2 & valence electrons & $\begin{array}{l}\text { ability to obtain information from the periodical table for the atoms } \mathrm{O}, \mathrm{C} \text { and } \mathrm{Al} \text {; } \\
\text { subtasks } \mathrm{a}, \mathrm{b} \text { and } \mathrm{c} \text {, respectively }\end{array}$ \\
\hline 3 & electron octet & understanding the concept of electron octet \\
\hline 4 & $\begin{array}{c}\text { number and } \\
\text { nature } \\
\text { of chemical bonds }\end{array}$ & $\begin{array}{l}\text { understanding what compounds are possible based on reasoning. Subtasks: (a) } \\
\text { oxygen with four bonds without resonance or net charge, (b) tetraoxygen in square } \\
\text { form, (c) oxygen with three bonds without resonance or net charge, (d) halogen } \\
\text { compound with three bonds in the central atom, (e) noble gas compound, (f) carbon } \\
\text { exceeding the octet, (g) sulfur exceeding the octet, (h) fluoride as the central atom }\end{array}$ \\
\hline
\end{tabular}


Table 1. Cont.

\begin{tabular}{|c|c|c|}
\hline & $\begin{array}{l}\text { Reason } \\
\text { for Our Choice }\end{array}$ & Needed Student Accomplishment \\
\hline 5 & bond order & $\begin{array}{l}\text { understanding the bond order of diatomic compounds: } \mathrm{H}_{2}, \mathrm{~F}_{2}, \mathrm{O}_{2} \text { and } \mathrm{N}_{2} \text {; subtasks } \\
\mathrm{a}, \mathrm{b}, \mathrm{c} \text { and } \mathrm{d} \text {, respectively }\end{array}$ \\
\hline 6 & geometry & $\begin{array}{l}\text { understanding the geometry of molecules. Subtasks: (a) phosgene given as T-shape } \\
\text { in } 2 \mathrm{~d} \text {, (b) methane given as formula, (c) ammonia given as formula }\end{array}$ \\
\hline 7 & polarity & $\begin{array}{l}\text { understanding the polarity of molecules given as } 2 \mathrm{D} \text { planar drawings, subtasks (a) } \\
\mathrm{CH}_{4} \text {, (b) } \mathrm{CH}_{3} \mathrm{Cl} \text {, (c) } \mathrm{CH}_{2} \mathrm{Cl}_{2} \text {, and given as molecular formula subtasks (d) } \mathrm{H}_{2} \mathrm{O} \text {, (e) } \\
\mathrm{CO}_{2} \text {, (f) } \mathrm{NH}_{3}\end{array}$ \\
\hline $\mathrm{H}_{2} \mathrm{O}$ & $\begin{array}{l}\text { octet rule, } \\
\text { valence electron } \\
\text { repulsion model }\end{array}$ & $\begin{array}{l}\text { ability to apply basic bond rules of second-row elements and to resolve geometry } \\
\text { based on the bond structure and free electron pairs of the central atom }\end{array}$ \\
\hline $\mathrm{CH}_{2} \mathrm{O}$ & $\begin{array}{l}\text { octet rule, } \\
\text { valence electron } \\
\text { repulsion model }\end{array}$ & $\begin{array}{l}\text { ability to apply basic bond rules of second-row elements and to resolve geometry } \\
\text { based on the bond structure of the central atom }\end{array}$ \\
\hline $\mathrm{N}_{2} \mathrm{H}_{2}$ & $\begin{array}{l}\text { geometry, } \\
\text { octet rule, } \\
\text { valence electron } \\
\text { repulsion model }\end{array}$ & $\begin{array}{l}\text { ability to apply basic bond rules of second-row elements on a non-carbon molecule } \\
\text { and to resolve geometry when information about free electron pairs are needed }\end{array}$ \\
\hline $\mathrm{O}_{3}$ & $\begin{array}{l}\text { formal charge, } \\
\text { geometry, } \\
\text { resonance, } \\
\text { valence electron } \\
\text { repulsion model }\end{array}$ & $\begin{array}{l}\text { ability to adapt to situation where the oxygen does not form two bonds. Ability to } \\
\text { understand resonance and formal charge in order to decide the bond order and to } \\
\text { resolve geometry when information about free electron pairs is needed }\end{array}$ \\
\hline $\mathrm{CH}_{4} \mathrm{O}$ & $\begin{array}{l}\text { geometry, } \\
\text { octet rule, } \\
\text { valence electron } \\
\text { repulsion model }\end{array}$ & $\begin{array}{l}\text { ability to apply basic bond rules when atoms are given in an unconventional order } \\
\text { and to resolve geometry based on the bond structure and free electron pairs of the } \\
\text { central atoms }\end{array}$ \\
\hline $\mathrm{HCN}$ & $\begin{array}{l}\text { geometry, } \\
\text { octet rule, } \\
\text { valence electron } \\
\text { repulsion model }\end{array}$ & $\begin{array}{l}\text { ability to apply basic bond rules of second-row elements and to resolve geometry } \\
\text { based on the bond structure of the central atom }\end{array}$ \\
\hline $\mathrm{CO}_{3}^{2-}$ & $\begin{array}{l}\text { bond order, } \\
\text { formal charge, } \\
\text { geometry, } \\
\text { resonance, } \\
\text { valence electron } \\
\text { repulsion model }\end{array}$ & $\begin{array}{l}\text { ability to understand several concepts at the same time. Ability to adapt into } \\
\text { situation where the oxygen does not form two bonds. Ability to understand } \\
\text { resonance and formal charge in order to decide the bond order and to associate } \\
\text { between formal charge and net charge. Ability to resolve geometry based on the } \\
\text { bond structure of the central atom }\end{array}$ \\
\hline $\mathrm{ClO}_{4}^{-}$ & $\begin{array}{l}\text { expanded octet, } \\
\text { formal charge, } \\
\text { geometry, } \\
\text { resonance, } \\
\text { valence } \\
\text { electrons, } \\
\text { valence electron } \\
\text { repulsion model }\end{array}$ & $\begin{array}{l}\text { ability to understand several concepts at the same time. Ability to calculate the total } \\
\text { number of valence electrons and match that with the final structure. Ability to adapt } \\
\text { into situation where oxygen does not form two bonds and where the octet rule does } \\
\text { not apply, because of d-orbitals of heavy central atom. Ability to understand } \\
\text { resonance and formal charge in order to decide the bond order and to associate } \\
\text { between formal charge and net charge. Ability to resolve geometry based on the } \\
\text { bond structure of the central atom }\end{array}$ \\
\hline $\mathrm{XeO}_{3}$ & $\begin{array}{l}\text { expanded octet, } \\
\text { formal charge, } \\
\text { geometry, } \\
\text { resonance, } \\
\text { valence } \\
\text { electrons, } \\
\text { valence electron } \\
\text { repulsion model }\end{array}$ & $\begin{array}{l}\text { ability to understand several concepts at the same time. Ability to calculate the total } \\
\text { number of valence electrons and match that with the final structure. Ability to adapt } \\
\text { into situation where the basic bond rules might not apply and where the octet rule } \\
\text { does not apply, because of d-orbitals of heavy central atom. Ability to understand } \\
\text { resonance and formal charge in order to decide the bond order and to associate } \\
\text { between formal charge and net charge. Ability to resolve geometry based on the } \\
\text { bond and free electron structure of the central atom }\end{array}$ \\
\hline
\end{tabular}


The drawing tasks were designed to test the features of the chemical structures that were assumed to be problematic for students to understand, and where possible heuristics can be seen. The drawing tasks in the pre- and post-tests included the sub-concepts of geometry, resonance, charge and expanded octet (see Table 1). Additionally, certain compounds measured systemic understanding, requiring an understanding of all the above-mentioned sub-concepts. The compounds in the pre-and post-tests were $\mathrm{H}_{2} \mathrm{O}$, $\mathrm{CH}_{2} \mathrm{O}, \mathrm{N}_{2} \mathrm{H}_{2}, \mathrm{O}_{3}, \mathrm{CH}_{4} \mathrm{O}, \mathrm{HCN}, \mathrm{CO}_{3}{ }^{2-}$ and $\mathrm{ClO}_{4}{ }^{-}$. The instructions for the pen-and-paper drawing tasks in both pre- and post-tests were: "Draw the following compounds as well as you can. Think about the angles between the bonds and the three-dimensional structure of the molecule. If the molecule can be drawn in many different ways, draw them all." Such a general instruction of the drawing task was given because the intention was not to distract the students with clues of the conceptions that are going to be analysed from the drawings.

Two weeks after the courses, the students took a written exam that included a drawing task that was also included in the evaluation. It tested the equivalent compounds to determine their polarity and geometry that were used also in the pre- and post-test. The compound used was $\mathrm{XeO}_{3}$. The exact same compounds that were used in the pre- and post-tests were not used in order to avoid learning from the previous task. During the tests, the students were not allowed to use any material, except the periodic table supplied.

\subsection{Data Analysis}

The data in the multiple-choice questions were classified either as a right or a wrong answer. If the student had chosen both options and thereby answered right and wrong, the answer was considered as wrong. A total of 67 answers in the pre-test and 20 answers in the post-test were missing and considered as "do not know".

Students' drawings of each molecular structure were categorized into five groups based on the quality of the drawing, indicating understanding related to sub-concepts and systemic understanding. Before the categorization, the researchers, two chemistry experts and one subject teacher of chemistry first discussed together the criteria for the evaluation of each structure. Classifications for the analyses were decided together. In general, categorization criteria were decided (e.g., what needs to be correctly drawn in order to reach certain category) as points for basic knowledge, such as for correct elements in the right order and correct bonds between the elements, and points for advanced knowledge, such as the ability to apply the information, for example, to the understanding of the expanded octets or the geometry of the molecular structure. When the classification was settled, all researchers rated the drawings.

In addition, the frequencies of ball-stick models and wrong and correctly drawn electrons were calculated from the drawings in the pre- and post-tests. If needed, the students' writings in their native language were translated into English. The drawings were reproduced so that the students could not be recognized by their handwriting.

The structure of water molecule was noticed to be very easy to draw for all students. There were no remarkable differences in these drawings and therefore, the drawings of $\mathrm{H}_{2} \mathrm{O}$ were not included in the data interpretation. In the pre-test, the other 1400 drawings (214 empty answers) were categorized into five different groups (Table 2, N/A = not analysed, meaning that the expert level could not be determined for these structures because of simplicity of the structure). 
Table 2. The number of drawings of 79 students in the pre- and post-tests $\left(\mathrm{CH}_{2} \mathrm{O}, \mathrm{N}_{2} \mathrm{H}_{2}, \mathrm{O}_{3}, \mathrm{CH} 4 \mathrm{O}, \mathrm{HCN}, \mathrm{CO}_{3}{ }^{2-}\right.$ and $\left.\mathrm{ClO}_{4}{ }^{-}\right)$and the drawings of 70 students $\left(\mathrm{XeO}_{3}\right)$ in the exams classified into five group. $\mathrm{N} / \mathrm{A}=$ the expert level was not determined for these structures.

\begin{tabular}{|c|c|c|c|c|c|c|c|c|c|c|c|c|c|c|c|}
\hline & \multicolumn{2}{|c|}{$\mathrm{CH}_{2} \mathrm{O}$} & \multicolumn{2}{|c|}{$\mathrm{N}_{2} \mathrm{H}_{2}$} & \multicolumn{2}{|c|}{$\mathrm{O}_{3}$} & \multicolumn{2}{|c|}{$\mathrm{CH}_{4} \mathrm{O}$} & \multicolumn{2}{|c|}{$\mathrm{HCN}$} & \multicolumn{2}{|c|}{$\mathrm{CO}_{3}^{2-}$} & \multicolumn{2}{|c|}{$\mathrm{ClO}_{4^{-}}$} & \multirow{2}{*}{$\begin{array}{l}\mathrm{XeO}_{3} \\
\text { Exam }\end{array}$} \\
\hline & Pre & Post & Pre & Post & Pre & Post & Pre & Post & Pre & Post & Pre & Post & Pre & Post & \\
\hline false & 6 & 3 & 6 & 6 & 6 & 1 & 8 & 7 & 7 & 3 & 19 & 11 & 33 & 16 & 1 \\
\hline primitive & 3 & 1 & 13 & 17 & 18 & 14 & 9 & 4 & 7 & 6 & 20 & 13 & 32 & 30 & 8 \\
\hline advanced & 15 & 21 & 47 & 42 & 47 & 39 & 43 & 39 & 9 & 5 & 33 & 31 & 12 & 22 & 18 \\
\hline more & 55 & 54 & 13 & 14 & 7 & 15 & 17 & 26 & 56 & 65 & 7 & 17 & 2 & 9 & 24 \\
\hline expert & $\mathrm{N} / \mathrm{A}$ & $\mathrm{N} / \mathrm{A}$ & $\mathrm{N} / \mathrm{A}$ & $\mathrm{N} / \mathrm{A}$ & 1 & 10 & 2 & 3 & $\mathrm{~N} / \mathrm{A}$ & $\mathrm{N} / \mathrm{A}$ & 0 & 7 & 0 & 2 & 19 \\
\hline
\end{tabular}

The first group of students' drawings were considered as the false drawings (Table 2, Figure 1), which did not show any knowledge due to mistakes or misconceptions or not answering. The structures were not correct at all, for example, wrong elements or wrong number of elements were used in the drawings; see $\mathrm{CH}_{4} \mathrm{O}$ and $\mathrm{ClO}_{4}{ }^{-}$in Figure 1A drawn by students $\mathrm{S} 31$ and $\mathrm{S} 1$, respectively, in the pre-test. In the structure of $\mathrm{CH}_{4} \mathrm{O}$, the student has not understood the concept of elemental composition. For some reason, the number of carbon atoms has been multiplied by four. In the structure of $\mathrm{ClO}_{4}{ }^{-}$, one oxygen atom is missing, most probably by mistake. Typically, these false structures seemed to be drawn by testing and contingency; no rules of the Lewis model were applied.

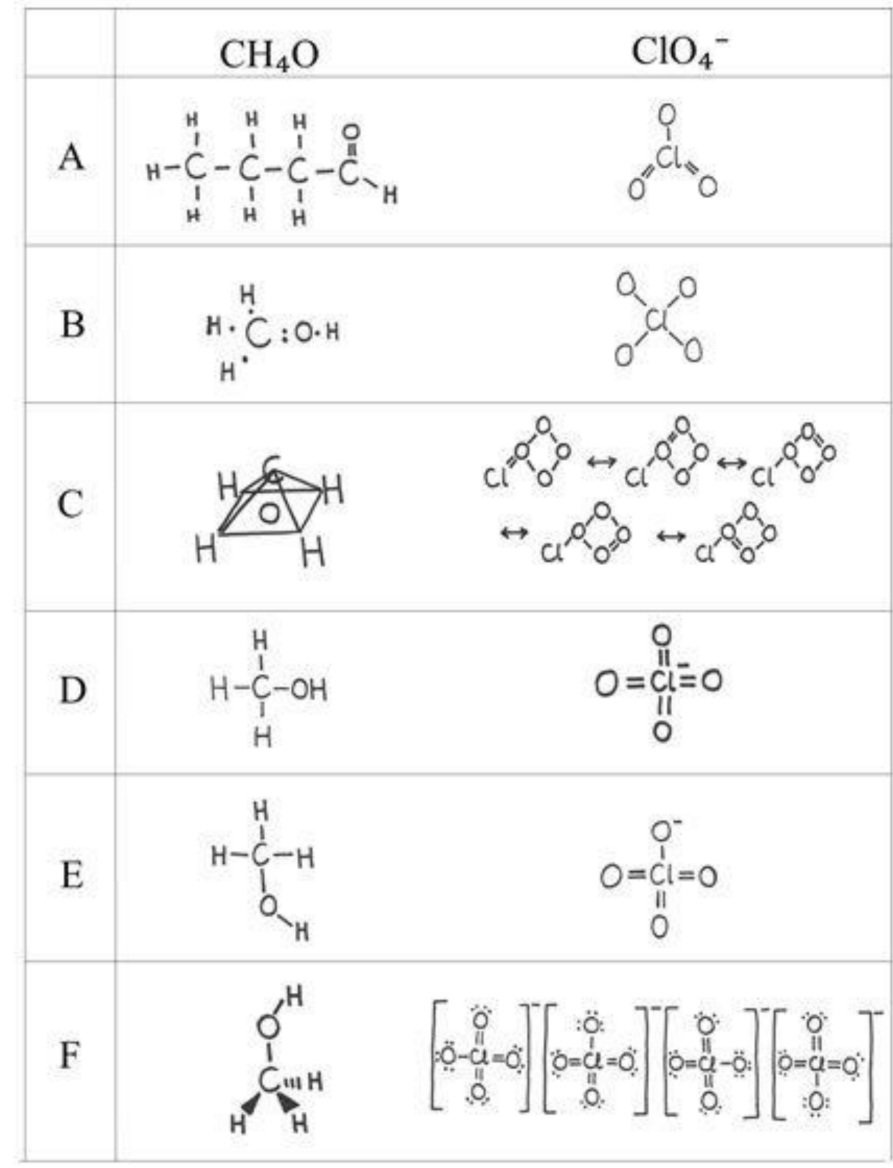

Figure 1. Examples of the structures of $\mathrm{CH}_{4} \mathrm{O}$ and $\mathrm{ClO}_{4}{ }^{-}$drawn by the students classified as (A) false, (B) primitive (showing basic knowledge), (C) primitive (showing creativity or applied knowledge), (D) advanced, (E) more advanced and (F) expert drawings. 
The second group was considered as primitive drawings (Table 2). This group represented some knowledge in the drawings. For example, these primitive structures with only a little basic knowledge contained the correct elements in the correct order; see, for example, $\mathrm{CH}_{4} \mathrm{O}$ and $\mathrm{ClO}_{4}{ }^{-}$in Figure $1 \mathrm{~B}$ drawn by students $\mathrm{S} 39$ and $\mathrm{S} 29$, respectively, in the pre-test. However, the nature or order of the bonds was not understood. For example, in the structure of $\mathrm{CH}_{4} \mathrm{O}$ electrons are missing and in the structure of $\mathrm{ClO}_{4}{ }^{-}$the bond order is wrong (Figure 1B). Most probably, the bonds and the electrons were drawn by testing. The structures showing only a little advanced knowledge had basic mistakes, such as the wrong elements, but showed some evidence of advanced knowledge. See, for example, the structures in Figure 1C drawn by students $S 47$ and S 16, respectively. The example for $\mathrm{CH}_{4} \mathrm{O}$ is taken from the pre-test and the example for $\mathrm{ClO}_{4}{ }^{-}$is taken from the post-test. For example, there is an idea of a three-dimensional structure for $\mathrm{CH}_{4} \mathrm{O}$, but it is not correct. In this case, the student had supplemented the structure by a statement: "Methane has bended as a tent over the oxygen so that the carbon atom is at the highest point and the hydrogen atoms are like tent poles". Moreover, there is an idea of resonance for $\mathrm{ClO}_{4}{ }^{-}$ in Figure 1B, but there are several misconceptions in the structure drawn. In addition, based on these structures, it is hard to evaluate whether the student actually understood the geometry or the resonance or just happened to guess right.

The third group consisted of advanced drawings, which included the correct elements in the correct order with correct bonds; see $\mathrm{CH}_{4} \mathrm{O}$ in Figure 1D drawn by student $\mathrm{S} 6$ in the pre-test. In addition, the structures containing the correct elements in the correct order showing some evidence of advanced knowledge such as the concepts of geometry, expanded octet or resonance, but also misconceptions, such as wrong nature or order of the bonds, were classified into this group. See, for example, the structure of the $\mathrm{ClO}_{4}{ }^{-}$in Figure 1D drawn by student $S 46$ in the pre-test. The student seemed to know the elements of the second period and the simple rules, such as HONC-1234, and therefore drew the structures and bonds correctly. The students may know more but did not show it. They mastered the chemistry that is taught in Finnish upper secondary schools.

The more advanced drawings were grouped into the fourth group. These drawings contained all basic things but had also some advanced knowledge, such as geometry, resonance, expanded octet or the formal charge of the molecule, but they did not show all of these. Misconceptions were not recognized. For example, the structure of $\mathrm{CH}_{4} \mathrm{O}$ in Figure $1 \mathrm{E}$ drawn by student S157 in the pre-test represented the correct elements in the correct order with the correct bonds and the geometry of the oxygen atom, but not for the carbon atom. Similarly, the structure of $\mathrm{ClO}_{4}{ }^{-}$in Figure 1E drawn by student $\mathrm{S} 42$ in the pre-test represented the correct basic items in addition to the expanded octet, but did not show any evidence of the geometry or resonance. Nonetheless, the students were able to apply their knowledge.

The fifth group consisted of expert drawings. These drawings were competent and contained almost all details indicating systemic understanding; see, for example $\mathrm{CH}_{4} \mathrm{O}$ drawn by student $\mathrm{S} 32$ in the pre-test and $\mathrm{ClO}_{4}{ }^{-}$drawn by student $\mathrm{S} 60$ in the post-test in Figure 1F. The structure shown for $\mathrm{ClO}_{4}{ }^{-}$is the best drawing showing the charge, the resonance and the expanded octet, but not the geometry. The students seemed to master all concepts needed. No misconceptions were recognized and the mnemonics, such as the HONC-1234 rule, did not restrict the chemical thinking. This group accounted for $<1 \%$ of all drawings. However, the structures of $\mathrm{CH}_{2} \mathrm{O}, \mathrm{N}_{2} \mathrm{H}_{2}$ and $\mathrm{HCN}$ were simpler to draw in comparison to the structures of $\mathrm{O}_{3}, \mathrm{CH}_{4} \mathrm{O}, \mathrm{CO}_{3}{ }^{2-}$ and $\mathrm{ClO}_{4}{ }^{-}$and there were not so many concepts to be understood; therefore, the expert level was not determined for these drawings (Table 2, marked as not analysed).

Similarly, in the post-test, 553 drawings ( 29 empty answers) were grouped into five groups (Table 2). The drawings of $\mathrm{XeO}_{3}$ (utilized in the course exam) are equivalent by their conceptual nature to the drawings of $\mathrm{ClO}_{4}{ }^{-}$(utilized in the pre-test and post-test), and therefore they are also discussed here in detail. 
Changes in the answers between pre- and post-tests to multiple-choice questions were classified as "both right", meaning that the answer was right both in the pre- and post-tests; as "improved", meaning that the answer changed from wrong to right or from do not know to right, or from wrong to do not know; as ""not improved", meaning that the answer was do not know or wrong in both tests; and as "declined", meaning that the answer changed from do not know to wrong or from right to do not know, or from right to wrong. In addition, the changes in the drawings and their classifications were evaluated. The conceptual change was thought to happen in such cases where the classification of the drawing moved clearly up in the classes and the misconceptions disappearedsuch as a primitive drawing with mistakes changed to an expert drawing without any misconceptions.

Statistical comparisons between group means were run with the IBM SPSS statistics 25 software (IBM, Armonk, NY, USA) by using $t$-test.

\section{Results}

\subsection{Understanding of Molecular Structures in Multiple-Choice Tasks}

In the pre-test answers, there were notable differences in students' knowledge quality and level related to molecular structures measured via multiple-choice questions (Table 3). On average, a student knew 16 out of 26 items of the multiple-choice questions (SD: 4,9; Min 0; Max 24). In general, the students knew quite well the bond order, as the majority of students succeeded in the four different questions of the bond order of diatomic molecules. Therefore, it was surprising that all students did not know that two electrons are needed to form a covalent bond (Table 3).

Table 3. The answers (\%) in the multiple-choice questions in the pre- and post-test and the changes in the knowledge between the tests. The numbers in the brackets refer to the initial questionnaire.

\begin{tabular}{|c|c|c|c|c|c|c|c|c|c|c|}
\hline & \multicolumn{3}{|c|}{ Pre-Test $(n=200)$} & \multicolumn{3}{|c|}{ Post-Test $(n=79)$} & \multicolumn{4}{|c|}{ Change } \\
\hline & Right & Wrong & $\begin{array}{l}\text { Do Not } \\
\text { Know }\end{array}$ & Right & Wrong & $\begin{array}{l}\text { Do Not } \\
\text { Know }\end{array}$ & $\begin{array}{l}\text { Both } \\
\text { Right }\end{array}$ & Improved & $\begin{array}{c}\text { Not } \\
\text { Improved }\end{array}$ & Declined \\
\hline covalent bond (1) & 80 & 17 & 3 & 100 & 0 & 0 & 89 & 11 & 0 & 0 \\
\hline $\begin{array}{l}\text { valence electrons of } \mathrm{O} \\
\text { (2a) }\end{array}$ & 62 & 26 & 13 & 96 & 4 & 0 & 73 & 23 & 4 & 0 \\
\hline $\begin{array}{l}\text { valence electrons of } C \\
(2 b)\end{array}$ & 75 & 13 & 13 & 97 & 3 & 0 & 85 & 13 & 1 & 1 \\
\hline $\begin{array}{l}\text { valence electrons of } \\
\mathrm{Al}(2 \mathrm{c})\end{array}$ & 68 & 18 & 15 & 94 & 4 & 3 & 76 & 18 & 5 & 1 \\
\hline octet (3) & 49 & 24 & 28 & 56 & 27 & 18 & 41 & 22 & 16 & 22 \\
\hline \multicolumn{11}{|l|}{$\begin{array}{c}\text { possible } \\
\text { compound? } \\
\mathrm{CH}_{3}\end{array}$} \\
\hline $\begin{array}{c}\left.\right|_{\mathrm{CH}_{3}}-\mathrm{CH}_{3} \mathrm{C}-\mathrm{O}-\mathrm{CH} \\
\text { (4a) }\end{array}$ & 79 & 14 & 7 & 86 & 13 & 1 & 75 & 13 & 6 & 6 \\
\hline & 53 & 31 & 17 & 46 & 37 & 18 & 35 & 13 & 33 & 19 \\
\hline $\begin{array}{l}\mathrm{C}_{\mathrm{CH}} \\
(4 \mathrm{c})\end{array}$ & 73 & 24 & 4 & 78 & 19 & 3 & 71 & 10 & 5 & 14 \\
\hline
\end{tabular}


Table 3. Cont.

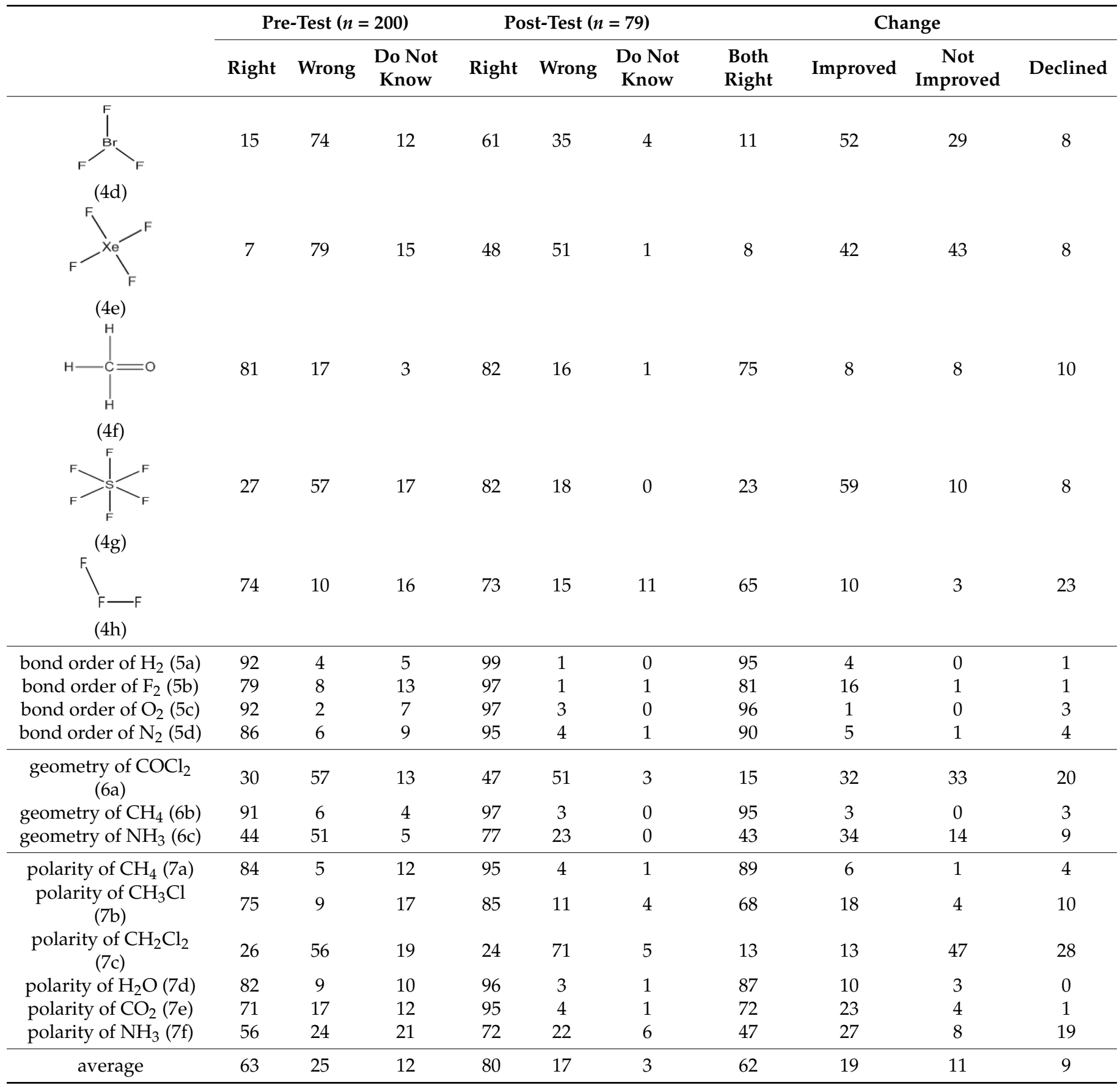

Several students did not know the number of the valence electrons of $\mathrm{O}, \mathrm{C}$ or $\mathrm{Al}$ even though they could use the periodic table. Other challenging things were the geometries and polarities of the molecules. On average, half of all students had the right answers for the multiple-choice questions $6 \mathrm{a}-\mathrm{c}$ dealing with geometry, and more than half for questions $7 \mathrm{a}-\mathrm{f}$ dealing with polarity (Table 2 ). These two things are linked together. The polarity as such is understood quite well, but if the student does not know the geometry of the molecule, it is hard to say anything about its polarity. In addition, the molecular structures with halogens and noble gases were difficult to understand. For example, the minority of the students knew that the structure $4 \mathrm{~d}$ was possible and even fewer students thought that the structure $4 \mathrm{e}$ was real (Table 3). One student mentioned to the teacher of the chemistry 
course that in secondary school, "it has been taught that the noble gases do not form compounds with other elements".

In the post-test, the lowest level of right answers was 11 and the highest 26, i.e., higher than in the pre-test. On average, a student knew 21 items $(\mathrm{SD}=2.7)$ of the multiplechoice questions. Thus, the level of the students' knowledge has increased markedly $(t(78)=-6.543, p<0.000)$. All students knew that two electrons are needed to form a covalent bond (Table 3). In addition, almost all students knew the number of the valence electrons of $\mathrm{O}, \mathrm{C}$ or Al. This time, the students knew even better the bond order. In addition, the knowledge of the geometry increased-more students had the right answers to the multiple-choice questions $6 \mathrm{a}-\mathrm{c}$ dealing with geometry and to questions $7 \mathrm{a}-\mathrm{f}$ dealing with polarity (Table 3). The students knew significantly better the molecular structures with halogens and noble gases, such as the above-mentioned structures $4 \mathrm{~d}$ and $4 \mathrm{e}$ (Table 3 ).

Altogether, $62 \%$ of the answers were unchanged and "both right" in the pre- and posttests (Table 3). However, 19\% of the answers had a positive change, i.e., were "improved", between the tests (Table 3). The greatest change in understanding, i.e., the change from wrong to right, was observed in question $4 \mathrm{~g}$ related to expanded octet. In addition, similar improvements were observed in the questions $4 \mathrm{~d}$ (Xe compound), 4e (tetraoxygen), $6 \mathrm{a}$ (geometry) and 6c (geometry, Table 3). In total, 11\% of the answers were "not improved" between the tests (Table 3). The unchanged wrong answer revealed the most difficult questions. The level of understanding was relatively low in the questions measuring the understanding related to the possible structures of $\mathrm{O}_{4}, \mathrm{BrF}_{3}$ and $\mathrm{XeF}_{4}(4 \mathrm{~b}, 4 \mathrm{~d}$ and $4 \mathrm{e}$, respectively), the geometry of $\mathrm{COCl}_{2}(6 \mathrm{a})$ and the polarity of $\mathrm{CH}_{2} \mathrm{Cl}_{2}(7 \mathrm{c})$. The negative change "declined" took place in $9 \%$ of the answers (Table 3).

\subsection{The Development of Students' General Understanding and the Conceptual Change Based on the Drawings}

Analysis of the pre-test drawings revealed information about the knowledge of molecular structures. In particular, we look at four sub-concepts, (1) resonance, (2) formal and net charges, (3) expanded octet and (4) geometry, in addition to the systemic understanding of the Lewis structure. At the beginning, the concept of resonance was not greatly recognized among the students. The correct resonance forms of $\mathrm{O}_{3}$ were found only in four drawings. For $\mathrm{CO}_{3}{ }^{2-}$, the resonance structure was found only in one drawing. The most difficult was $\mathrm{ClO}_{4}{ }^{-}$, in which the resonance was applied to only one drawing, and was otherwise not correct. In addition, the students had clear difficulties in assigning the charge on a polyatomic ion. The correct assessment of charge required estimation of formal charges of individual atoms. The correct notation of charge of a molecule was made for $\mathrm{CO}_{3}{ }^{2-}$ and $\mathrm{ClO}_{4}{ }^{-}$by $9 \%$ and $17 \%$ of the students, respectively. Expanded octet was also a difficult concept, probably because previous education at the lower level concentrated heavily on organic compounds. The electron octet, which has in a centre role in basic Lewis structure, is not always valid. The student must master the decisive factors that will lead to disregarding the electron octets around the atoms. In case of $\mathrm{ClO}_{4}{ }^{-}, 14$ drawings contained expanded octet, and only in four drawings was this executed correctly. Regarding geometry, students in general seemed to lack spatial thinking and in multiple-choice tasks, they tried to analyse the polarity of the molecule from a 2-dimensional structure. Many of the student drawings lacked geometrical analysis or description of the 3-dimensional structure. In addition, the role of free electrons around the atom and its effect on the geometry was not well understood.

When comparing multiple-choice questions and drawings, certain connections were found. The most interesting was that the students who gave wrong answers related to covalent bonds in the multiple-choice task received lower scores in the drawing tasks in general $(\mathrm{t}(47.17)=2.55, p=0.014)$. This means that if the students do not understand the bonding model, it is hard to draw correct structures.

Analysis of the post-test drawings showed that the conceptions had changed and the level of the students' knowledge had increased markedly between the tests. In most cases, drawings were more professional. There were fewer mistakes and misconceptions and 
the students seemed to better understand the concept of elemental composition (Table 2, Figures 2 and 3A; the structures in Figure 3A were drawn by student $S 10$ and in Figure 3B by $S 30$ ). In addition, the general knowledge of the chemical bonds increased, which can be seen in Figure 2A.

(a)

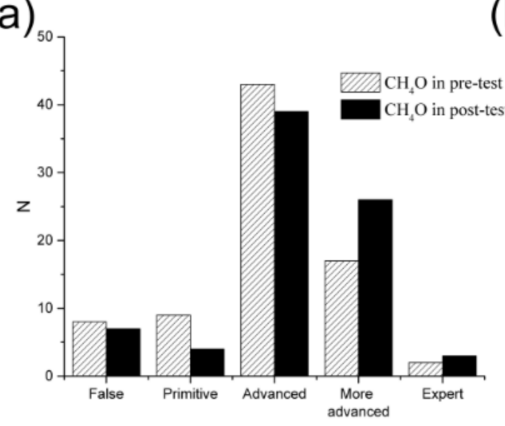

(c)

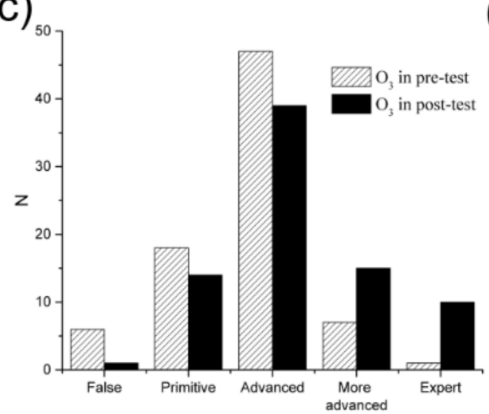

(b)

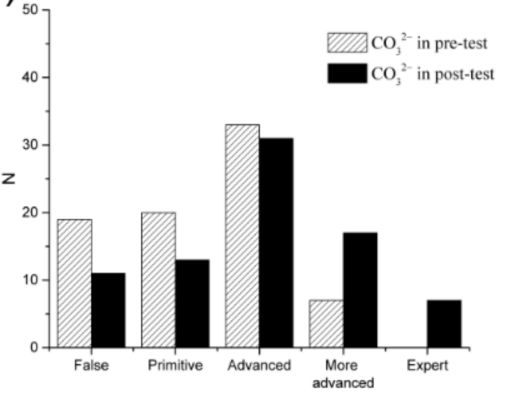

(d)

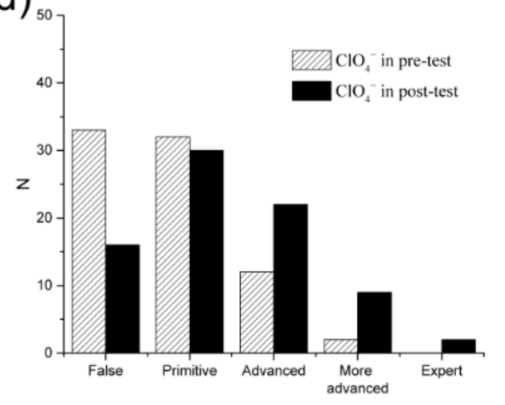

Figure 2. The distribution of the level of the drawings in the pre- and the post-tests for (a) $\mathrm{CH}_{4} \mathrm{O}$, (b) $\mathrm{CO}_{3}{ }^{2-}$, (c) $\mathrm{O}_{3}$, and (d) $\mathrm{ClO}_{4}{ }^{-}$.

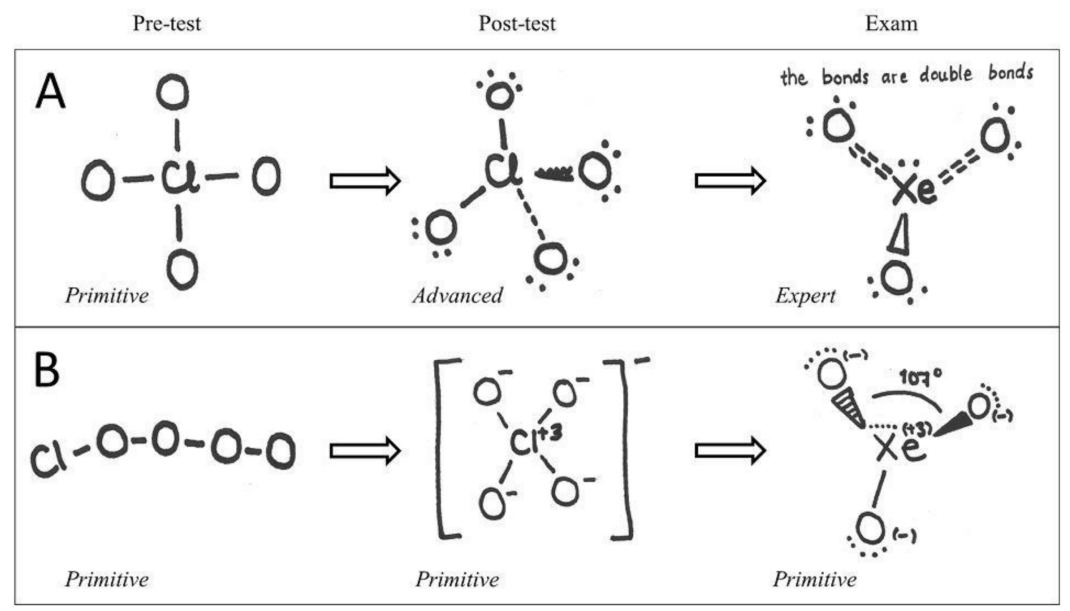

Figure 3. Examples showing the changes in the knowledge of the students during the pre-test, post-test and final exam using $\mathrm{ClO}_{4}{ }^{-}$and $\mathrm{XeO}_{3}$ as the model representations: $(\mathrm{A})$ an increase in the level of the student's knowledge; (B) the student's knowledge stays in the same conceptual level.

The fifth group consisting of expert drawings was larger in the post-test (Table 2). Their drawings were competent and contained almost all details; see, for example $\mathrm{ClO}_{4}{ }^{-}$in Figure 1E. The structure shown for $\mathrm{ClO}_{4}{ }^{-}$is the best drawing showing the charge, the resonance and the expanded octet, but not the geometry. The students drawing expert structures seemed to master all sub-concepts needed, and hence they seemed to have reached the level of systemic understanding. However, the sub-concepts examined were 
still difficult for some students. The improvement of understanding of resonance is seen in Figure $2 \mathrm{~B}, \mathrm{C}$ (for $\mathrm{CO}_{3}{ }^{2-}$ and $\mathrm{O}_{3}$ ). The apparent median is shifting to a higher category of understanding in both cases. However, in the post-test, only four students tried to draw the resonance structures for $\mathrm{ClO}_{4}{ }^{-}$and two students succeeded (see an example of the wrong answer in Figure 4A (S 56) and an example of the right answer in Figure 4B (S 37)). In the post-test, the students took the charge of the molecule into account more often (Figure 5; the structures drawn by students S 30 (A), S 20 (B), S 6 (C), S 24 (D), S 5 (E) and S 10 (F)). For example, $56 \%$ of the students took the charge into account for $\mathrm{ClO}_{4}{ }^{-}$(see an example of an attempt in Figure 5A) and $41 \%$ marked it correctly (see examples for correct drawings in Figure 5B,C). The students made also more attempts to draw the expanded octets; $37 \%$ of the students tried to draw the expanded octet for $\mathrm{ClO}_{4}{ }^{-}$(see an example of an attempt in Figure 6A (S 7)) and 16\% succeeded (see an example of the right answer in Figure 6B (S 6)). In addition, improvements in the consideration of geometry were detected, as seen, for example, in Figure 7. Some students drew the structures without geometry, such as in Figure 7A (S 4). In Figure 7B, student (S 48) took a stand on the geometry, but the structure was 2-dimensional. Some of the students drew 3-dimensional structures, as in Figure 7C (S 13).

A

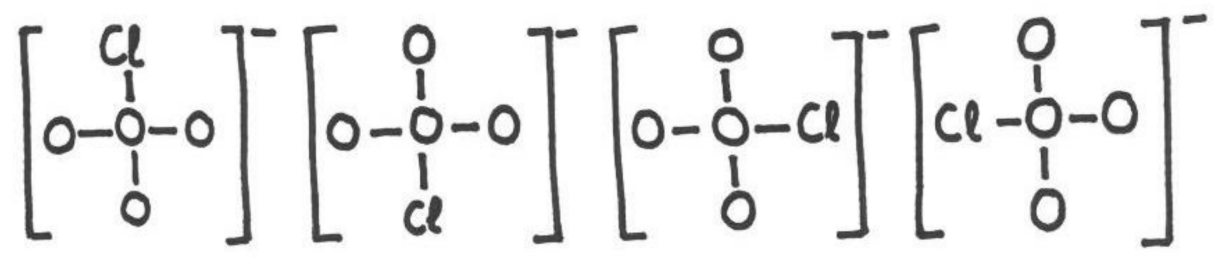

B

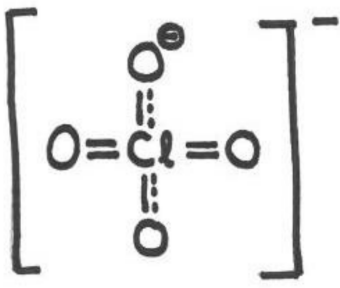

one or the other oxygen

has an extra electron (depending on the side of the double bond)

Figure 4. Examples showing the resonance structures for $\mathrm{ClO}_{4}{ }^{-}$in the post-test: (A) a wrong answer; (B) a correct answer.

A<smiles></smiles><smiles>O=CC(=O)O</smiles>

D<smiles>[Z]C1CCCC1=O</smiles>

E<smiles>[O-][Cl+3]([O-])([O-])[O-]</smiles><smiles>O=C([O-])[O-]</smiles>

F

Figure 5. Examples showing the charge of the molecule in the post-test for $\mathrm{ClO}_{4}{ }^{-}$: (A) a wrong answer; (B) an answer with a correct marking for the charge even though the structure itself is not correct; (C) a correct answer. For $\mathrm{CO}_{3}{ }^{2-}$ : (D) a wrong answer; (E,F) correct answers. 


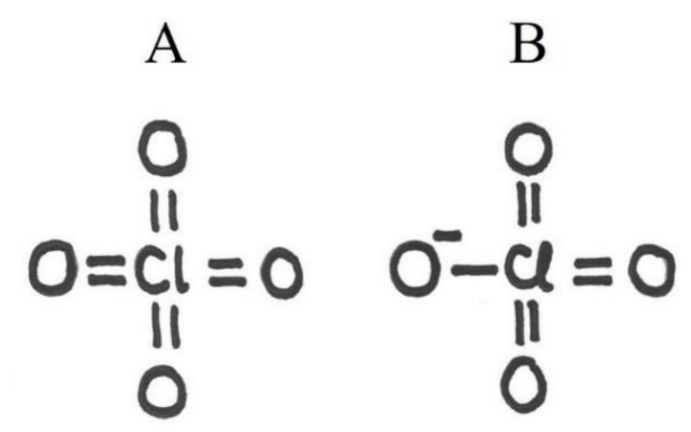

Figure 6. Examples showing the expanded octets for $\mathrm{ClO}_{4}{ }^{-}$in the post-test: (A) a wrong answer; (B) a correct answer.

A

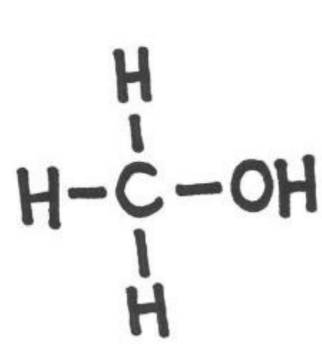

B

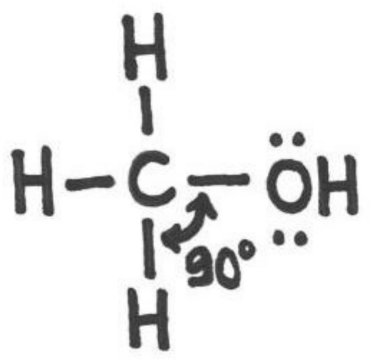

$\mathrm{C}$

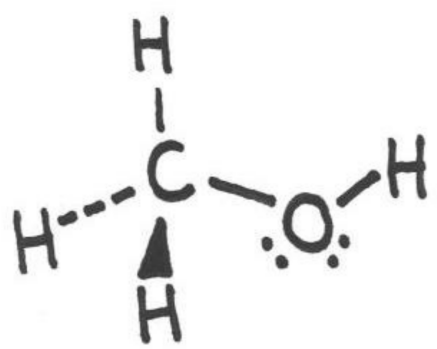

Figure 7. Examples showing the difficulties in the spatial thinking for $\mathrm{CH}_{4} \mathrm{O}$ : $(\mathbf{A})$ a structure without geometry; (B) a 2-dimensional structure; (C) a 3-dimensional structure.

The learning continued after the actual courses by self-education before the final exam. The students' knowledge had increased even more- there were fewer mistakes and misconceptions in the exam and the students seemed to understand the concepts better than in the post-test. In the exam, the students needed to assign the formal charge, take into account the expanded octet and understand the geometry when drawing the structure of $\mathrm{XeO}_{3}$. The drawings were remarkably better in the exam in comparison to their counterparts in the post-test (Figure 8 ). The differences in students' learning can be nicely seen from Figure 3, which shows the learning processes of two students. The first student learns during the course and understands the concepts; the molecular representations are changing from primitive to advanced to expert drawing (Figure 3A). Hence, this student had reached a conceptual change, whereas at the same time, the other student learns a little but still stays at the very same primitive level (Figure 3B).

The number of students were 200 in the pre-test and 79 in the post-test, which can raise the question of whether the students were really learning or whether only the most talented and motivated students participated in the post-test. As an example, six students who did not draw the easy representation of the water molecule in the pre-test did not participate in the post-test. Therefore, the results of the pre-test were rechecked in order to see whether there was a difference in the knowledge between the students who participated only in the pre-test or in both pre- and post-tests. The students participating only in the pre-test $(n=121)$ had on average $15 \pm 5(\mathrm{M}=15.4 ; \mathrm{SD}=5.40$; Min = 0; Max = 22) correct answers in the pre-test, whereas the students participating in both tests $(n=79)$ had $18 \pm 4(\mathrm{M}=18.06$; $\mathrm{SD}=3.51$; Min $=7$; $\mathrm{Max}=24$ ) correct answers in the pre-test, which indicates that students who struggled the most dropped off from the course. 


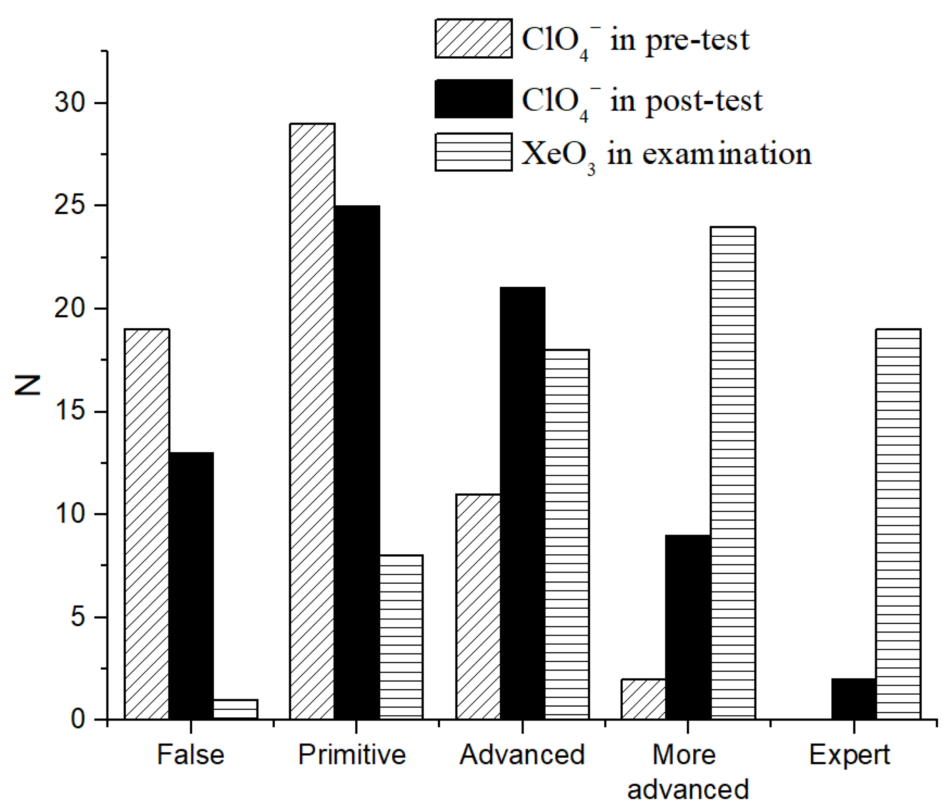

Figure 8. The distribution of the level of drawings suggesting systemic understanding in the preand post-tests $\left(\mathrm{ClO}_{4}^{-}\right)$, and in the examination $\left(\mathrm{XeO}_{3}\right)$.

\subsection{Heuristics Used in the Multiple-Choice Tasks and Drawings}

One especially striking feature in the molecular structures was the appearance of balland-stick models. Instead of drawing atoms with representative symbols, many structures were drawn by using spherical features as atoms which were connected together with sticks. The appearance of ball-and-stick models was $8-16 \%$ in the pre-test depending on the molecule drawn. In the post-test, there were fewer simple ball-and-stick models, i.e., $5-11 \%$ depending on the task. Instead, there were more electrons or electron pairs drawn to the structures, i.e., $27-44 \%$ depending on the task. In general, the students who drew ball-and-stick structures in the pre-test did not draw electrons in the post-test. For example, $16 \%$ of the students who participated also in the post-test drew a ball-and-stick structure for $\mathrm{CH}_{4} \mathrm{O}$ in the pre-test (Figure 9A). Only one of these students (S 62) drew the correct free electrons in the post-test (Figure 9B), meaning that $15 \%$ of the students could not do so. Instead, there were 17 students $(22 \%)$ who did not draw a ball-and-stick structure at all in the pre-test but had the correct electrons in the post-test. The very same applies to the other molecules and their representations.

A

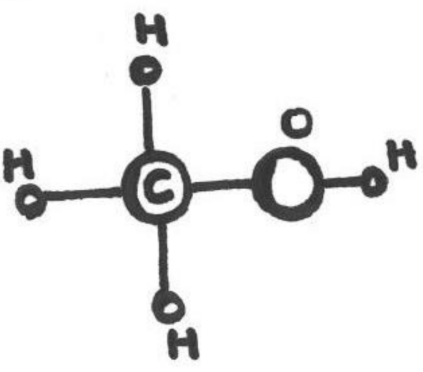

Pre-test
B

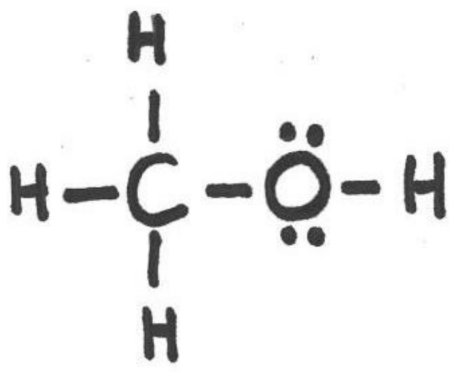

Post-test

Figure 9. Examples of the ball-and-stick models drawn in the pre-test (A) and the representations showing the electrons drawn in the post-test (B). The same student has drawn both representations.

The results showed that the memorized rules were used. The students remembered carbon with four bonds, nitrogen with three bonds, oxygen with two bonds and hydrogen 
with one bond, but other atoms are challenging $(4 \mathrm{~d}, 4 \mathrm{~g})$. They were also capable of distinguishing false structures based on these atoms as seen in the multiple-choice questions concerning oxygen with three bonds and carbon with five bonds $(4 \mathrm{c}, 4 \mathrm{f})$. Although they seemed to utilize an intuitive octet rule, it seemed clear that they were not calculating the total number of valence electrons. In the pre-test, $33 \%$ of students failed to answer correctly on the number of valence electrons of oxygen, but still succeeded in a multiple-choice question measuring the bond order of $\mathrm{O}_{2}$. The students often drew molecules with too many or too few electrons. That was realized in the structure of $\mathrm{ClO}_{4}{ }^{-}$, where one of the most common misconceptions was the representation with four single bonds. The same applied also for $\mathrm{CO}_{3}{ }^{2-}$ having three single bonds. Another implication of not calculating the electrons was the absence of free electron pairs, or the free electrons were drawn as decorations without awareness of the total number of valence electrons. Most often, the free electrons were placed near oxygen. The appearance of free electron pairs was 5-9\% depending on the molecules in the pre-test. The correct notation of electron pairs was found in $1-7 \%$ of drawings depending on the molecules.

\section{Discussion}

\subsection{Difficulties in Going beyond Basic Organic Compounds}

Our study revealed differences among the students participating in an introductory level university chemistry course in their understanding related to molecular structure concepts. Even the basic concepts of the covalent bond and valence electrons were not very clear to all students. If the very basic information about the bonding model is lacking, it is certainly hard to draw acceptable structures and understand the phenomena.

Some of the molecular concepts exceed the prior education. Quite surprisingly, one of these concepts is resonance. The concept of resonance plays a fundamental role in understanding the electronic structure and reaction properties of many molecules and ions. Mastering the concept of resonance requires advanced thinking. The students might not realize that, according to quantum theory, the electrons are not objects of classical mechanics and therefore they are not actually localized in their positions, corresponding to ontological misconceptions discussed by Chi [27]. This also contradicts the idea of molecules being rigid ball-and-stick structures. It might be difficult to understand that a best-drawn structure is not static but there are equal alternative bond and free electron organizations that have to be drawn in order to fully describe the molecule. The final system cannot be represented easily by a ball-and-stick model unless average structures (resonance hybrids) are being built. However, understanding average structures requires an understanding of the quantum mechanical nature of molecules, in that profound conceptual change and ontological shift are usually required [27].

Since the octet rule has been considered as a fundamental rule in previous education, the violation of the rule is unexperienced by the majority of the students. A similar observation was made by Erman [47], whereas Joki and Aksela [48] suggested that one reason for this could be the p-prim of vacuums impel (desire for fullness). In the pre-test, students generally rejected all the molecules that had atoms with more than four bonds and noble gas compounds were thought to be nonexistent. It was beyond their awareness that some atoms are able to form stable compounds by exceeding the electron octet by using d-orbitals from electron subshell. This concept expands the understanding of bonding in heavier elements, halogens and noble gases, but at the same time expands the number of concepts that have to be mastered. It also adds the degrees of freedom to the molecule construction, which might be confusing to some students. Cooper et al. [5] noticed that even faculty members can produce representations that contain more than eight electrons around nitrogen or oxygen atom. In addition, they noticed that students wanted to follow the octet rule and added electrons until the octet of each atom was full, even though there were not enough electrons available. Strong obedience towards the octet rule was also shown in the pre-test of our study, realized by the maximum of four bonds per atom and 
the nonexistence of noble gas compounds. It seems that many students are locked in on an idea of simple and familiar molecular structures.

With this level of understanding, the representation of molecules is entirely intuitive and lacking a systematic approach. Despite the shortcomings, the students were still proficient to produce a geometrically valid water molecule. In fact, the structure of a water molecule was noticed to be very easy to draw for all students. There were no remarkable differences in these drawings and therefore, the drawings of $\mathrm{H}_{2} \mathrm{O}$ were not included in the data interpretation. Based on this observation, it is actually quite hard to say whether the students really understood how the water molecule is represented or did they just happened to remember the structure shown earlier. This supports the idea that some molecules are visually familiar, meaning that the structure of the molecule is remembered well from previous experience. Cooper et al. [5] noticed that the success in producing the correct structure was highly dependent on how the chemical formula was presented to the students. They noticed that about $60 \%$ of the students drew the right structure for $\mathrm{CH}_{4} \mathrm{O}$ but over $90 \%$ of the students could draw the same required structure for $\mathrm{CH}_{3} \mathrm{OH}$. They suggested that students were relying on memorized cues rather than the actual use of Lewis rules. Our findings support the same. Many of the students were successful in the bond order task even without comprehension of the number of valence electrons of an atom. Therefore, the physical nature of a bond is obscure to them. This is a clear indicator of relying on simple memorized rules to cope. Furthermore, it might be that the simple rules have been beneficial for better success in previous education.

\subsection{Heuristics Hindering the Understanding of Lewis Model}

Some students drew simple ball-and-stick structures without further information such as the symbols of elements (e.g., Figure 9A). This might indicate of a desire for familiar structure, a visual image of an ideal molecule. This drawn ball-and-stick representation might be the vague projection of this visual image. However, it must be noted that also some of the students who drew correct structural representations drew additional balland-stick structures. The basis for this simplified thinking is created well in advance. In elementary school, the structure of water is taught as the ears of Mickey Mouse or as rabbit ears $[49,50]$. The pupils might remember the shape of the molecule but otherwise there are no good reasons for doing this [51]. Laing concludes that the rabbit ear model, i.e., the tetrahedral sp3 model, for the bonding in water is not satisfactory and it is not necessary [51]. Similar simplification continues later as the ball-and-stick models are used to show the geometry of the molecule and they might be the most common molecular representations in the chemistry textbooks. This may hinder the development of critical thinking in chemistry problem-solving situations.

This study showed that if the student drew the ball-and-stick models in the pre-test, he or she was not likely capable of drawing the correct Lewis structures with electrons in the post-test. This indicates that locking in on oversimplified ideas might prevent learning progression. Similar observations were made by Williamson et al. [52], who noticed that the students who spent more time on the ball-and-stick representations, when asked about the positive charge, were less likely to be correct than the students who spent more time with the electrostatic potential map identified via eye tracking. Ball-andstick models represent the shape of the molecule but do not indicate the distribution of electrons, whereas the electrostatic potential maps presents the electrons with a colorcoded representation [53]. Hinze et al. also noticed that the participants with greater prior knowledge began to effectively apply the electrostatic potential maps on inference problems with practice, whereas the participants with low prior knowledge maintained their reliance on ball-andstick representations and therefore were more likely to answer questions incorrectly [53]. It seems to be so that the use of ball-and-stick models reflects a lower level of understanding and also hinders the development of understanding. Ferk et al. have warned that chemistry teachers should be cautious when using molecular 
models in teaching so that they do not create misconceptions on the basis of the models about the size, shape or colours of atoms or molecules [54].

It is also worthwhile to consider whether the ball-and-stick models were ever intended to be drawn by hand or just meant for the illustration of the geometry of the molecule. It has also been criticized that often the function of the models in the science classroom is to aid remembering or comprehending concepts and the models are presented from the scientists' view [55], but the teachers should take into account also the students' view in order to allow students to better understand the models and develop more sophisticated processes, such as explanations and interpretations [55].

\subsection{Systemic Understanding and Conceptual Change in the Understanding of Lewis Model}

Systemic understanding demands that all sub-concepts are understood and thus often requires that conceptual change in the level of mental models is achieved. Students need to break out from the simple familiar molecule idea and undertake conceptual change from naïve structures to complex understanding. There were some concepts for students that were hard to learn. $\mathrm{ClO}_{4}{ }^{-}$is a good example of a representation where the students need to assign the formal charge, take into account the expanded octet and understand the geometry when drawing the structure. The students might be able to manage rather difficult concepts when they are presented separately. Combining the difficult concepts into one task makes it much more difficult to solve. Perhaps the most important thing here is not the difficulty of one concept but the entity taking into account all aspects-the skill of systemic thinking.

It has been proposed that when the students start to use models, their understanding should be reviewed for problematic interpretations, and also the arbitrary nature of models should be made explicit [56]. Students need a conceptual change in relation to chemistry as a discipline and they need to consider the drawing of molecular structures as problem-solving instead of just mechanical execution. On the whole, the upper secondary school teaching might be fairly generalizing and feeding the idea of simplified molecular structures. The main characteristics are described, such as "this molecule has the V-shape", but it is not explained why the shape of the molecule is like that. The geometry is taught to students in secondary school, but it is supported by the ball-and-stick models in the figures and perhaps these ball-and-stick models were therefore heavily exploited in the representations the students delivered in this study.

According to our findings, there were notable changes in understanding the concept of resonance in the structures of $\mathrm{O}_{3}$ and $\mathrm{CO}_{3}{ }^{2-}$. That is realized in the post-test, with a higher number of students in more advanced and in expert levels, but still, resonance remained quite a difficult concept. The majority of the students did not produce resonance structures in the post-test. The difficulty is probably due to the diffused nature of the concept [57]. Likewise, there was a great increase in the correct answers in the multiple-choice questions concerning the expanded octet of $\mathrm{SF}_{6}(4 \mathrm{~g})$. The same kind of conceptual change did not take place in the drawing task of $\mathrm{ClO}_{4}{ }^{-}$. Despite a considerable increase in those who attempted to exceed the octet of chloride, the number of correct drawings in terms of expanded octet was low. The result might be due to the fact that in the drawing task, there are so many concepts that have to be managed at the same time as discussed above. Resonance and expanded octet are advanced concepts and cannot be produced easily by using molecular building blocks, as the ball-and-stick models are usually too rigid for this. If the student is conceptually oriented to physical building blocks, the orientation might disturb the learning process. As an indication, we observed a notable number of triangular $\mathrm{O}_{3}$ and a few linear $\mathrm{ClO}_{4}{ }^{-}$structures as they could be done with the building blocks. We observed also a notable number of halogens drawn with either one bond or four bonds instead of expanded octet.

According to the pre-test, only a minority of the students were able to make a notation of the charge in the drawn molecule and even fewer placed it in the correct position. In the beginning, the notation of the charge might be spontaneous behaviour. For example, in 
$\mathrm{CO}_{3}{ }^{2-}$, they might consider it as an anion for carbonic acid and after deprotonation, two oxygens are left with negative charge. Furthermore, the charge might have been understood by a broken ball-and-stick model so that the charge is compensating the missing atom. It is unexpected that they would calculate the formal charges in the pre-test, since the formal charge can be considered as an unknown concept to them. We cannot directly estimate the ability of the students to calculate the formal charges because we did not ask them to mark the formal charges in the drawings. We can only make judgements based on the outcomes. For molecules such as $\mathrm{ClO}_{4}{ }^{-}$and $\mathrm{XeO}_{3}$, it is necessary to perform the estimation of formal charges in order to produce the correct structure. Based on the emerging success of these structures, the students are in the progress of learning the concept.

\subsection{Limitations}

This study provides important and novel knowledge related to university students' understanding related to molecular structures. However, there are some limitations in this study that need to be taken into account when generalizing the results of this study. The study was performed at one institution only, so results may be different at other universities or in other countries. The students' background variables, such as age, gender, previous education and work experiences, were not analysed, so the results may be more typical for specific groups of students. The understanding of molecular structures and conceptual change were evaluated on the basis of drawing tasks and thereby it was based on the interpretation of the representations made by the authors. Interviews could have revealed important aspects related to students' thinking. The participation was voluntary and the questionnaires were filled during the lecture times, so not all students were reached through questionnaires. There were fewer participants in the later lectures and therefore, the number of participants was remarkably lower in the post-test, leaving room for biased results. Thus, the results are likely more positive than they would have been if all students had participated. Those students who struggled the most dropped off from the course, so it was not possible to study their difficulties with learning. Exploring those students' learning skills and approaches could shed more light on their difficulties [58].

\section{Conclusions}

The aim of this study was to explore university students' understanding and changes in their conceptions as a result of an introductory chemistry course related to molecular structures. The goal of the course was to teach all students the contents, but the hypothesis was that some students will still possess some misconceptions after the course. Our assumption was that heuristics hinder the learning of more complex molecular structures. In general, the level of the students' knowledge increased markedly and there were fewer mistakes and misconceptions. The chemistry concepts are complex and several matters must be understood at the same time, requiring systemic understanding in order to allow the students to solve complex problems in their future chemistry tasks. Helping students to focus on interrelated concepts instead of unconnected facts or using heuristics in science classrooms would facilitate critical thinking and high-level learning of complex scientific phenomena, such as molecular structures.

The results of this study highlight that learning molecular structures often requires conceptual change related to several sub-concepts since students have a lot of intuitive knowledge-some of which is erroneous and connected to heuristics-when they begin their chemistry studies at university. Higher education teachers should be aware of these typical challenges related to learning in order to support systemic understanding and conceptual change. A special concern should be pointed towards students who are conceptually oriented to building blocks, i.e., the ball-and-stick models. There is a group of students who might have performed well in previous education by relying on elementary and sometimes naïve rules of thumb. They might be so tightly locked in on their ideal image of familiar molecules that this cognitive orientation disturbs the further learning process. Students may create so-called synthetic models, which means that they may seem to 
possess new understanding, but because it is based on their old knowledge structures and ignores the conflict between old and new information, it is not fully understood (Vosniadou and Brewer, 1992). It would be important to support students to learn that understanding molecular structures requires problem-solving and profound systemic understanding and critical thinking of underlying sub-concepts instead of utilizing simple mnemonics or rules of thumb.

Author Contributions: Conceptualization, M.K., M.M. (Mari Murtonen) and M.S.; methodology, M.K.; M.M. (Mari Murtonen). and M.S.; software, M.M. (Marianna Manninen); validation, I.S., M.K., M.M. (Marianna Manninen), M.M. (Mari Murtonen)., and M.S.; formal analysis, M.K., M.M. (Marianna Manninen), and M.S.; investigation, M.K., M.M. (Marianna Manninen) and M.S; resources, M.K, and M.S..; data curation, M.K., M.M. (Marianna Manninen), and M.S.; writing-original draft preparation, I.S., M.K., M.M. (Mari Murtonen) and M.S.; writing—review and editing, I.S., M.K., M.M. (Marianna Manninen), M.M. (Mari Murtonen), and M.S.; visualization, M.M. (Marianna Manninen); supervision, I.S. and M.M. (Mari Murtonen); project administration, M.K.. and M.S.; All authors have read and agreed to the published version of the manuscript.

Funding: This research received no external funding.

Institutional Review Board Statement: Voluntary participation, informed consent, and anonymity of the participants were ensured in the research process. The study did not involve intervention in the physical integrity of the participants, deviation from informed consent, studying children under the age of 15 without parental consent, exposure to exceptionally strong stimuli, causing long-term mental harm beyond the risks of daily life, or risking participants' security (cf. Finnish Advisory Board on Research Integrity 2019). Consequently, this study did not require a Finnish ethics review.

Informed Consent Statement: Informed consent was obtained from all subjects involved in the study.

Data Availability Statement: The data presented in this study are available on request from the corresponding authors.

Conflicts of Interest: The authors declare no conflict of interest.

\section{References}

1. Cooper, M.M.; Corley, L.M.; Underwood, S.M. An investigation of college chemistry students' understanding of structure-property relationships. J. Res. Sci. Teach. 2013, 50, 699-721. [CrossRef]

2. McClary, L.; Talanquer, V. Heuristic reasoning in chemistry: Making decisions about acid strength. Int. J. Sci. Educ. 2011, 33, 1433-1454. [CrossRef]

3. Murtonen, M.; Salmento, H. Broadening the theory of scientific thinking for higher education. In Redefining Scientific Thinking for Higher Education: Higher-Order Thinking, Evidence-Based Reasoning and Research Skills; Murtonen, M., Balloo, K., Eds.; Palgrave Macmillan: London, UK, 2019; pp. 3-29.

4. Lewis, G.N. The atom and the molecule. J. Am. Chem. Soc. 1916, 38, 762-785. [CrossRef]

5. Cooper, M.M.; Grove, N.; Underwood, S.M. Lost in Lewis structures: An investigation of student difficulties in developing representational competence. J. Chem. Ecol. 2010, 87, 869-874. [CrossRef]

6. Cooper, M.M.; Underwood, S.M.; Hilley, C.Z.; Klymkowsky, M.W. Development and assessment of a molecular structure and properties learning progression. J. Chem. Educ. 2012, 89, 1351-1359. [CrossRef]

7. Suidan, L.; Badenhoop, J.K.; Glendening, E.D.; Weinhold, F. Common textbook and teaching misrepresentations of Lewis structures. J. Chem. Educ. 1995, 72, 583-586. [CrossRef]

8. Purser, G.H. Lewis structures are models for predicting molecular structure, not electronic structure. J. Chem. Educ. 1999, 76, 1013-1018. [CrossRef]

9. Eilam, B. System thinking and feeding relations: Learning with a live ecosystem model. Instr. Sci. 2012, 40, 213-239. [CrossRef]

10. Wadouh, J.; Liu, N.; Sandmann, A.; Neuhaus, B.J. The effect of knowledge linking levels in biology lessons upon students knowledge structure. Int. J. Sci. Math. Educ. 2014, 12, 25-47. [CrossRef]

11. Barak, J.; Sheva, B.; Gorodetsky, M.A.; Gurion, B. As 'process' as it can get: Students' understanding of biological processes. Int. J. Sci. Educ. 1999, 21, 1281-1292. [CrossRef]

12. Verhoeff, R.P.; Waarlo, A.J.; Boersma, K.T. Systems modelling and the development of coherent understanding of cell biology. Int. J. Sci. Educ. 2008, 30, 543-568. [CrossRef]

13. Brandstädter, K.; Harms, U.; Großschedl, J. Assessing system thinking through different concept-mapping practices. Int. J. Sci. Educ. 2012, 34, 2147-2170. [CrossRef]

14. Bransford, J.; Brown, A.; Cocking, R. How People Learn: Brain, Mind, Experience and School: Expanded Edition of Sciences; The National Academy Press: Washington, DC, USA, 2000. 
15. Sinatra, G.M.; Mason, L. Beyond knowledge: Learner characteristics influencing conceptual change. In International Handbook on Conceptual Change Research; Vosniadou, S., Ed.; Routledge: New York, NY, USA, 2013; pp. 377-394.

16. Broughton, S.H.; Sinatra, G.M.; Nussbaum, E.M. "Pluto has been a planet my whole life!" Emotions, attitudes, and conceptual change in elementary students' learning about Pluto's reclassification. Res. Sci. Educ. 2013, 43, 529-550. [CrossRef]

17. Carey, S. Conceptual Change in Childhood; MIT Press: Cambridge, UK, 1985; ISBN 0-262-03110-8.

18. Chinn, C.A.; Brewer, W.F. The role of anomalous data in knowledge acquisition: A theoretical framework and implications for science instruction. Rev. Educ. Res. 1993, 63, 1-49. [CrossRef]

19. Diakidoy, I.-A.N.; Kendeou, P.; Ioannides, C. Reading about energy: The effects of text structure in science learning and conceptual change. Contemp. Educ. Psychol. 2003, 28, 335-356. [CrossRef]

20. Duit, R.; Treagust, D.F. Conceptual change: A powerful framework for improving science teaching and learning. Int. J. Sci. Educ. 2003, 25, 671-688. [CrossRef]

21. Limón, M. On the cognitive conflict as an instructional strategy for conceptual change: A critical appraisal. Learn. Instr. 2001, 11, 357-380. [CrossRef]

22. Mason, L. Responses to anomalous data on controversial topics and theory change. Learn. Instr. 2001, 11, 453-483. [CrossRef]

23. Vosniadou, S. Capturing and modeling the process of conceptual change. Learn. Instr. 1994, 4, 45-69. [CrossRef]

24. Vosniadou, S.; Skopeliti, I. Developmental shifts in children's categorization of the earth. In Proceedings of the XXVII Annual Conference of the Cognitive Science Society, Stresa, Italy, 21-23 July 2005; Bara, B.G., Barsalou, L., Bucciarelli, M., Eds.; Lawrence Erlbaum Associates: Mahwah, NJ, USA, 2005; pp. 2325-2330.

25. Carey, S. Science education as conceptual change. J. Appl. Dev. Psychol. 2000, 21, 13-19. [CrossRef]

26. Amin, T.; Levrini, O. Converging Perspectives on Conceptual Change; Routledge: New York, NY, USA, 2018.

27. Chi, M.T.H. Two kinds and four sub-types of misconceived knowledge, ways to change it, and the learning outcomes. In International Handbook of Research on Conceptual Change; Vosniadou, S., Ed.; Routledge: New York, NY, USA, 2013 ; pp. 49-70.

28. Limón, M.; Mason, L. Prologue. In Reconsidering Conceptual Change: Issues in Theory and Practice; Limón, M., Mason, L., Eds.; Kluwer Academic Publishers: Dordrecht, The Netherlands, 2002; pp. 15-20.

29. Posner, G.J.; Strike, K.A.; Hewson, P.W.; Gertzog, W.A. Accommodation of a scientific conception: Toward a theory of conceptual change. Sci. Educ. 1982, 66, 211-227. [CrossRef]

30. Potvin, P.; Nenciovici, L.; Malenfant-Robichaud, G.; Thibault, F.; Sy, O.; Mahhou, M.A.; Bernard, A.; Allaire-Duquette, G.; Blanchette Sarrasin, J.; Brault Foisy, L.-M.; et al. Models of conceptual change in science learning: Establishing an exhaustive inventory based on support given by articles published in major journals. Stud. Sci. Educ. 2020, 56, 1-55. [CrossRef]

31. Chi, M.T.H. Three types of conceptual change: Belief revision, mental model transformation, and categorical shift. In Handbook of Research on Conceptual Change; Vosniadou, S., Ed.; Lawrence Erlbaum Associates, Inc.: Hillsdale, NJ, USA, 2008 ; pp. 61-82.

32. Chi, M.T.H. Quantifying qualitative analyses of verbal data: A practical guide quantifying qualitative analyses of verbal data: A practical guide. J. Learn. Sci. 1997, 6, 271-315. [CrossRef]

33. Chi, M.T.H. Commonsense conceptions of emergent processes: Why some misconceptions are robust. J. Learn. Sci. 2005, 14, 161-199. [CrossRef]

34. Vosniadou, S.; Brewer, W.F. Mental models of the earth: A study of conceptual change in childhood. Cogn. Psychol. 1992, 24, 535-585. [CrossRef]

35. Flaig, M.; Simonsmeier, B.A.; Mayer, A.-K.; Rosman, T.; Gorges, J.; Schneider, M. Conceptual change and knowledge integration as learning processes in higher education: A latent transition analysis. Learn. Individ. Differ. 2018, 62, 49-61. [CrossRef]

36. Södervik, I.; Virtanen, V.; Mikkilä-Erdmann, M. Challences in understanding photosynthesis in a university introductory biociences class. Int. J. Sci. Math. Educ. 2015, 13, 733-750. [CrossRef]

37. Treagust, D.F.; Duit, R. Conceptual change: A discussion of theoretical, methodological and practical challenges for science education. Cult. Stud. Sci. Educ. 2008, 3, 297-328. [CrossRef]

38. Duit, R.; Treagust, D.F. Conceptual change: Still a powerful framework for improving the practice of science instruction. In Issues and Challenges in Science Education Research: Moving Forward; Tan, K.C.D., Kim, M., Eds.; Springer: Dordrecht, The Netherlands, 2012; pp. 43-54. ISBN 9789400739802.

39. Tiettmeyer, J.M.; Coleman, A.F.; Balok, R.S.; Gampp, T.W.; Duffy, P.L.; Mazzarone, K.M.; Grove, N.P. Unraveling the complexities: An investigation of the factors that induce load in chemistry students constructing Lewis structures. J. Chem. Educ. 2017, 94, 282-288. [CrossRef]

40. Guzzetti, B.J.; Snyder, T.E.; Glass, G.V.; Gamas, W.S. Promoting conceptual change in science: A comparative meta-analysis of instructional interventions from reading education and science education. Read. Res. Q. 1993, 28, 116-159. [CrossRef]

41. Üce, M.; Ceyhan, İ. Misconception in chemistry education and practices to eliminate them: Literature analysis. J. Educ. Train. Stud. 2019, 7, 202-208. [CrossRef]

42. Aw, J.K.; Boellaard, K.C.; Tan, T.K.; Yap, J.; Loh, Y.P.; Colasson, B.; Blanc, É.; Lam, Y.; Fung, F.M. Interacting with three-dimensional molecular structures using an augmented reality mobile app. J. Chem. Educ. 2020, 97, 3877-3881. [CrossRef]

43. Mason, L.; Gava, M.; Boldrin, A. On warm conceptual change: The interplay of text, epistemological beliefs, and topic interest. J. Educ. Psychol. 2008, 100, 291-309. [CrossRef] 
44. Mikkilä-Erdmann, M. Text comprehension and conceptual change: Interaction between text design and levels of text comprehension. In Reframing the Processes of Conceptual Change: Integrating Theory and Practice; Mason, L., Limón, M., Eds.; Kluwer Academic Publishers: Dordrecht, The Netherlands, 2002; pp. 337-356.

45. Tippett, C.D. Refutation text in science education: A review of two decades of research. Int. J. Sci. Math. Educ. 2010, 8, 951-970. [CrossRef]

46. Nkosi, T.; Mnguni, L. The impact of physical molecular models on students' visuo-semiotic reasoning skills related to the lewis structure and ball \& stick model of ammonia. J. Balt. Sci. Educ. 2020, 19, 594-604.

47. Erman, E. Factors contributing to students' misconceptions in learning covalent bonds. J. Res. Sci. Teach. 2017, 54, 520-537. [CrossRef]

48. Joki, J.; Aksela, M. The challenges of learning and teaching chemical bonding at different school levels using electrostatic interactions instead of the octet rule as a teaching model. Chem. Educ. Res. Pract. 2018, 19, 932-953. [CrossRef]

49. Bagnoli, F. Bursting money bins, the ice and water structure. Europhys. News 2015, 46, 15-16. [CrossRef]

50. Hague, G.R.J. The magic of chemistry: Learning it is fun! J. Chem. Educ. 1983, 60, 741-743. [CrossRef]

51. Laing, M. No rabbit ears on water. The structure of the water molecule: What should we tell the students? J. Chem. Educ. 1987, 64, 124-128. [CrossRef]

52. Williamson, V.M.; Hegarty, M.; Deslongchamps, G.; Williamson, K.C.; Shultz, M.J. Identifying student use of ball-and-stick images versus electrostatic potential map images via eye tracking. J. Chem. Educ. 2013, 90, 159-164. [CrossRef]

53. Hinze, S.R.; Rapp, D.N.; Williamson, V.M.; Shultz, M.J.; Deslongchamps, G.; Williamson, K.C. Beyond ball-and-stick: Students' processing of novel STEM visualizations. Learn. Instr. 2013, 26, 12-21. [CrossRef]

54. Ferk, V.; Vrtacnik, M.; Blejec, A.; Gril, A. Students ' understanding of molecular structure representations. Int. J. Sci. Educ. 2003, 25, 1227-1245. [CrossRef]

55. Criswell, B. Do you see what I see? Lessons about the use of models in high school chemistry classes. J. Chem. Educ. 2011, 88, 415-419. [CrossRef]

56. Harrison, A.G.; Treagust, D.F. Learning about atoms, molecules, and chemical bonds: A case study of multiple-model use in grade 11 chemistry. Sci. Educ. 2000, 84, 352-381. [CrossRef]

57. Kerber, R.C. If it's resonance, what is resonating? J. Chem. Educ. 2006, 83, 223-227. [CrossRef]

58. Lastusaari, M.; Laakkonen, E.; Murtonen, M. Persistence in studies in relation to learning approaches and first-year grades: A study of university chemistry students in Finland. Chem. Educ. Res. Pract. 2019, 20, 452-467. [CrossRef] 